\title{
Altered Auditory Processing, Filtering, and Reactivity in the Cntnap2 Knock-Out Rat Model for Neurodevelopmental Disorders
}

\author{
Kaela E. Scott, $₫$ Ashley L. Schormans, Katharine Y. Pacoli, Cleusa De Oliveira, Brian L. Allman,*

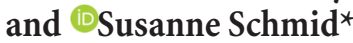 \\ Department of Anatomy and Cell Biology, Schulich School of Medicine and Dentistry, The University of Western Ontario, London, Ontario N6A 5C1, Canada
}

\begin{abstract}
Sensory processing, and auditory processing in particular, is altered in individuals with neurodevelopmental disorders such as autism spectrum disorders (ASDs). The typical maturation of the auditory system is perturbed in these individuals during early development, which may underlie altered auditory reactivity that persists in later life. Of the many genes that regulate the auditory system development, loss-of-function mutations in the CNTNAP2 gene are strongly associated with language processing deficits and ASD. Therefore, using a novel Cntnap2 knock-out rat model, we tested the impact of Cntnap2 loss on auditory processing, filtering, and reactivity throughout development and young adulthood in male and female animals. Although hearing thresholds were not altered in Cntnap2 knock-out animals, we found a reduction in response amplitudes and a delay in response latency of the auditory brainstem response (ABR) in juvenile Cntnap2 knock-out rats compared with age-matched controls. Amplitudes and latency of the ABR largely normalized by adulthood, indicating a delayed maturation of auditory processing pathways in Cntnap 2 knock-out rats. Despite the reduced ABR amplitudes, adolescent Cntnap2 knock-out animals displayed increased startle reactivity accompanied by disruptions in sensory filtering and sensorimotor gating across various conditions, most of which persisted in adulthood. All of these observations show striking parallels to disruptions reported in ASD. Our results also imply that developmental disruptions of sensory signal processing are associated with persistent changes in neural circuitries responsible for implicit auditory evoked behavior, emphasizing the need for interventions that target sensory processing disruptions early during development in ASD.
\end{abstract}

Key words: auditory; autism; brainstem; neurodevelopment; sensory processing; startle

Significance Statement

This is the first study of brainstem auditory processing in a novel knock-out rat model with very high construct and face validity for autism spectrum disorders. Electrophysiological and behavioral measures of implicit auditory-evoked responses were systematically taken across developmental stages. Auditory processing, filtering, and reactivity disruptions show striking similarities to observations in autism. We also show for the first time that, whereas auditory brainstem responses normalize by adulthood, disruptions in brainstem-mediated auditory-evoked behavior persist. This indicates that early developmental perturbations in sensory processing can cause permanent maladaptive changes in circuitries responsible for auditory reactivity, underlining the importance for interventions early during development aiming at normalizing sensory processing.

\section{Introduction}

The auditory system undergoes tremendous remodeling and plasticity in early development, which has a profound effect on

\footnotetext{
Received March 22, 2018; revised Aug. 13, 2018; accepted Aug. 14, 2018.

Author contributions: K.E.S. wrote the first draft of the paper; K.E.S., B.L.A., and S.S. edited the paper. K.E.S. B.L.A., and S.S. designed research; K.E.S., A.L.S., K.Y.P., and C.D.O. performed research; K.E.S., A.L.S., and K.Y.P. analyzed data.

This work was supported by the Natural Sciences and Engineering Research Council (NSERC) of Canada, the Canadian Institutes of Health Research (CIHR), and a BrainScan Stimulus grant by the Canada First Research Excellence Fund.

The authors declare no competing financial interests.
}

how the adult brain handles acoustic information. The typical maturation is perturbed in individuals with neurodevelopmental disorders, such as autism spectrum disorder (ASD), which can ultimately lead to long-term auditory processing deficits (for review, see Sinclair et al., 2017). Apart from varying degrees of

\footnotetext{
*B.L.A. and S.S. are co-senior authors.

Correspondence should be addressed to Susanne Schmid, Department of Anatomy and Cell Biology, Schulich School of Medicine and Dentistry, The University of Western Ontario, London, Ontario N6A 5C1, Canada. E-mail: susanne.schmid@schulich.uwo.ca.

DOI:10.1523/JNEUROSCI.0759-18.2018

Copyright $@ 2018$ the authors $\quad 0270-6474 / 18 / 388588-17 \$ 15.00 / 0$
} 
language impairment (Kjelgaard and Tager-Flusberg, 2001; Deriziotis and Fisher, 2017), individuals with ASD have shown deficits in how their central auditory system processes the basic features of sound (Hitoglou et al., 2010), including delayed neurotransmission throughout the successive relay nuclei of the brainstem (Wong and Wong, 1991; Rosenhall et al., 2003; Kwon et al., 2007; Tas et al., 2007; Fujikawa-Brooks et al., 2010; Magliaro et al., 2010; Gonçalves et al., 2011; Roth et al., 2012; Miron et al., 2016). Furthermore, self-report questionnaires (Danesh et al., 2015) and psychoacoustic testing (Khalfa et al., 2004) have provided evidence of increased sensitivity to sound in the autism population. Related to this hyperacusis, the implicit (reflexive) reactivity to acoustic stimuli, a behavioral measure reliant on auditory brainstem function, is greater in some individuals with ASD, as revealed by exaggerated responses to sudden sounds (Chamberlain et al., 2013; Kohl et al., 2014; Takahashi et al., 2016). At present, however, the developmental trajectory of these electrophysiological and behavioral indices of auditory brainstem dysfunction has not been fully elucidated because they are difficult to study longitudinally in patient populations. It is therefore not clear whether these deficits are already present in early life, if they improve/worsen with age, or how auditory processing disruptions affect auditory reactivity.

To date, a limited number of preclinical studies have examined ASD-related auditory processing deficits using rodents with gene mutations linked to ASD. In 2011, Peñagarikano et al. first characterized a mutant mouse model with a loss-of-function mutation of the contactin associated protein-like 2 gene (Cntnap2). Homozygous loss-of-function mutations in CNTNAP2 are a rare single gene cause for ASD (Strauss et al., 2006; Poot, 2017) and multiple studies have identified various other CNTNAP2 mutations being associated with, or a risk factor for, ASD and language-related disorders (Alarcón et al., 2008; Arking et al., 2008; Rodenas-Cuadrado et al., 2014, 2016; Murphy and BenítezBurraco, 2017; Poot, 2017). CNTNAP2, which codes for the neurexin CASPR2, is known to be in important in language development in humans, with its structure and biological functions appearing to be conserved (Abrahams et al., 2007; Newbury et al., 2011; Whalley et al., 2011; Whitehouse et al., 2011; Poot, 2015). CASPR2 is highly expressed throughout the mammalian auditory pathway within brainstem structures including the spiral ganglion cells of the auditory nerve, cochlear nucleus, lateral superior olive, paralemniscal nucleus, and the inferior colliculus in mice (Gordon et al., 2016). In a series of studies, Cntnap2 mutant mice showed reduced vocalizations and an impaired auditory temporal processing (Peñagarikano et al., 2011; Truong et al., 2015). Despite the high construct validity of these Cntnap2 mutant mice, it remains unknown how a deficiency in Cntnap2 affects the time course of maturation of brainstem-mediated auditory processing and behavior.

In the present study, we used genetically modified rats to investigate the developmental trajectory of Cntnap2-related deficits in electrophysiological and behavioral measures of brainstem function in male and female juvenile, adolescent, and adult Cntnap2 homozygous (Cntnap2 $2^{-1-}$ ) and heterozygous (Cntnap $2^{+/-}$) knock-out animals compared with wild-type controls $\left(\right.$ Cntnap $\left.2^{+/+}\right)$. Consistent with electrophysiological testing in humans, the four characteristic waves of the rat auditory brainstem response (ABR) to acoustic stimuli were used to assess hearing sensitivity (i.e., hearing threshold), neural responsivity (i.e., ABR wave amplitude), and speed of neurotransmission (i.e., ABR wave latency) across development, which provided an index of the reliability of auditory information processing. Behaviorally, reflexive responses to startle-eliciting sounds were used to determine how Cntnap2 dysfunction affected the maturation of acoustic reactivity, sensory filtering (i.e., habituation), and sensorimotor gating (i.e., prepulse inhibition, PPI). Overall, the present study provides the first comprehensive investigation of the direct contribution of the autism-linked gene CNTNAP2 to the development of brainstem-mediated auditory processing and behavior and, in doing so, has validated a new rat model for studying auditory brainstem dysfunction with high relevance to neurodevelopmental disorders.

\section{Materials and Methods}

Animals. Male and female Sprague Dawley wild-type (Cntnap $2^{+/+}$), heterozygous knock-out (Cntnap $2^{+/-}$), and homozygous knock-out $\left(\right.$ Cntnap $2^{-1-}$ ) rats were used in this study. Mutant breeders were obtained from Horizon Discovery and wild-type breeders from Charles River Laboratories. Experimental animals were obtained from the following crossings: Cntnap2 $2^{-1-}$ rats from homozygous knock-out crossings; Cntnap $2^{+1-}$ rats from crossings of wild-type and Cntnap $2^{-1-}$ rats; and wild-type rats from wild-type crossings. Animals from a minimum of three litters of a given genotype were used in all experiments. Date of birth was designated as postnatal day zero (P0). Rats were weaned on P21 and sexes were separated on P35. Rats were housed in a temperature-controlled room on a $12 \mathrm{~h}$ light/dark cycle with ad libitum food and water. Electrophysiological and behavioral testing was performed during the light phase of the cycle (lights on at 07:00 h) and across age to gain insight into developmental changes in sensory processing. The electrophysiological assessment of the ABRs was performed at three time points in each rat: juvenile (P28 or P29; referred to as P28), adolescent (P42 or P43; referred to as P42), and adulthood (P70 or P71; referred to as P70). The behavioral assessment of auditory brainstem function, as well as spontaneous locomotor activity, was assessed when rats were between P36 and P41 (referred to as P38) and between P72 and P85 (referred to as P78). All experimental procedures were approved by the University of Western Ontario Animal Care Committee and were in accordance with the guidelines established by the Canadian Council on Animal Care.

ABRs. The level of sound-evoked electrical activity in the brainstem was measured using an established protocol (Schormans et al., 2016) to assess hearing sensitivity, neural responsivity, and speed of neurotransmission in juvenile, adolescent, and adult rats of the three genotypes (wild-type: 10 males, 7 females; Cntnap $2^{+/-}: 11$ males, 11 females; and Cntnap $^{-1-}$ : 12 males, 10 females). Rats were anesthetized with ketamine (P28: $40 \mathrm{mg} / \mathrm{kg}$ or P42 and P70: $80 \mathrm{mg} / \mathrm{kg}$, i.p.) and xylazine (P28: $2.5 \mathrm{mg} / \mathrm{kg}$ or P42 and P70: $5 \mathrm{mg} / \mathrm{kg}$, i.p.) and placed in a double-walled sound-attenuating chamber. Subdermal electrodes (27 gauge; Rochester Electro-Medical) were positioned at the vertex (active electrode), over the right mastoid process (reference electrode), and on the midback (ground electrode; Fig. 1A). Throughout the electrophysiological assessment, body temperature was maintained at $\sim 37^{\circ} \mathrm{C}$ using a homeothermic heating pad (507220F; Harvard Apparatus).

The acoustic stimuli used in the ABR assessment consisted of a click ( $0.1 \mathrm{~ms}$ ) and 2 tones $(4 \mathrm{kHz}$ and $20 \mathrm{kHz} ; 5 \mathrm{~ms}$ duration and $1 \mathrm{~ms}$ rise/fall time), which were generated using a Tucker-Davis Technologies RZ6 processing module sampled at $100 \mathrm{kHz}$. A magnetic speaker (MF1; Tucker-Davis Technologies) positioned $10 \mathrm{~cm}$ from the animal's right ear was used to deliver the stimuli and its left ear was blocked with a custom foam plug. The acoustic stimuli were each presented 1000 times (21 times/s) at decreasing intensities from 90 to $40 \mathrm{~dB}$ sound pressure level (SPL) in $10 \mathrm{~dB}$ SPL steps and at $5 \mathrm{~dB}$ SPL steps from $40 \mathrm{~dB}$ SPL to 5 $\mathrm{dB}$ SPL. At the lower sound intensities, each stimulus was presented twice. Consistent with previous studies, each rat's hearing sensitivity (i.e., ABR threshold) for the click and tonal stimuli was determined using the criterion of just noticeable deflection of the averaged electrical activity within a $10 \mathrm{~ms}$ window (Popelar et al., 2008; Abitbol et al., 2016; Schormans et al., 2016; Fig. 1B). Before the ABR assessment, the acoustic stimuli were calibrated with custom MATLAB software (The Math- 
A

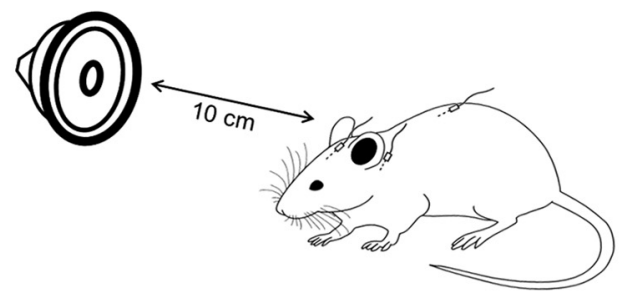

\section{C}

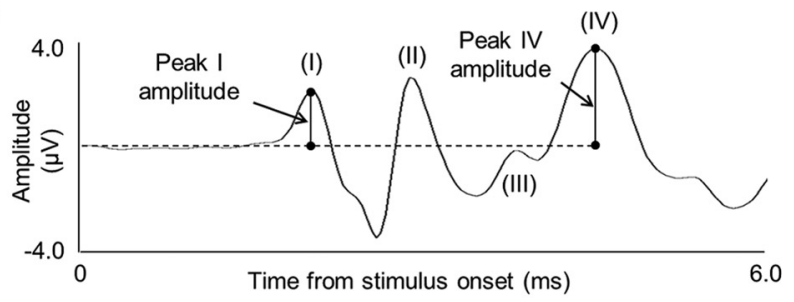

D

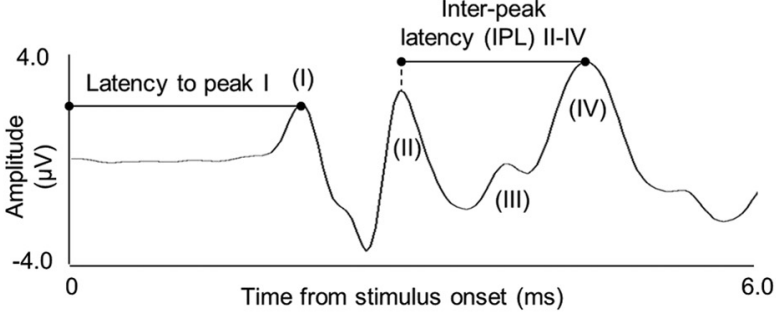

B
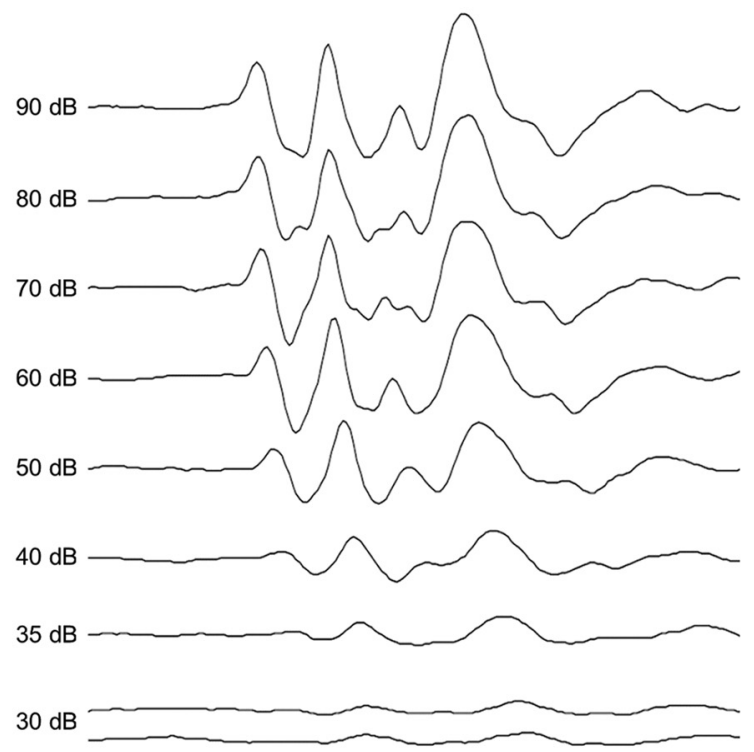

$25 \mathrm{~dB}$

$20 \mathrm{~dB}$

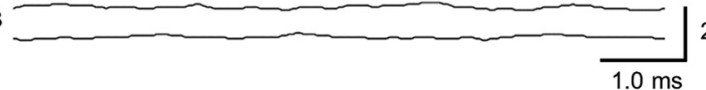

Figure 1. ABR methodology. $A$, Positioning of magnetic speaker and subdermal electrodes for the recording of the ABR. $B$, Representative example of an adult wild-type rat's ABR to a click stimulus used to determine hearing threshold. The last noticeable deflection of the averaged electrical activity can be seen at $25 \mathrm{~dB} \mathrm{SPL}$. C, D, Representative ABR trace from a wild-type animal in response to a $90 \mathrm{~dB}$ SPL click stimulus depicts the four characteristic ABR waves in rats and the measurement for peak amplitudes and latencies (black bars).

Works) using a 1/4-inch microphone (2530; Larson Davis) and preamplifier (2221; Larson Davis).

The sound-evoked activity associated with the ABR assessment was collected using a low-impedance head stage (RA4L1; Tucker-Davis Technologies), preamplified and digitized (RA16SD Medusa preamp; Tucker-Davis Technologies), and sent to a RZ6 processing module via a fiber-optic cable. The signal was filtered $(300-3000 \mathrm{~Hz})$ and averaged using BioSig software (Tucker-Davis Technologies). The peak amplitudes of each of the characteristic positive waves of the rat ABR were measured in microvolts in reference to the baseline $(0 \mu \mathrm{V}$; Fig. $1 C)$ and the latency of each of these peaks was determined from the stimulus onset (Fig. 1D). Because ABR waves IV/V are often described as a complex, with wave V riding on wave IV (Alvarado et al., 2012), for a wave peak to be analyzed, it must have a preceding and following trough less than its maximum. This resulted in the consistent presence of peaks for waves I-IV at $90 \mathrm{~dB}$ SPL. Interpeak latencies were calculated by subtracting the timing of the respective peaks (e.g., wave IV - wave II). The experimenter was blinded to the animal's genotype for all analysis associated with the ABR assessment.

Acoustic startle responses (ASRs). To investigate the developmental maturation of brainstem-mediated responses to startle-eliciting sounds, rats of the three genotypes were tested at P38 and P78.

The assessment of acoustic reactivity, sensory filtering, and sensorimotor gating was conducted in sound-attenuating startle boxes (LE116; Panlab) using the StartFear system (Panlab) and STARTLE software module (PACKWIN-CSST, PACKWIN version 2.0; Panlab). Animals were placed into large plastic tubes, and set on a weight transducing platform in the sound-attenuating chamber. Before the behavioral procedures associated with the ASR (i.e., acoustic reactivity, sensory filtering, and sensorimotor gating) animals were handled and acclimated to the startle boxes over three 10 min sessions. During these acclimation sessions, only background noise (60 dB SPL, white noise) was presented to the animals.

Following acclimation, behavioral procedures were conducted over $3 \mathrm{~d}$. On day one, each animal's acoustic reactivity was assessed by deter- mining the relationship between the intensity of a given acoustic stimulus and the magnitude of the elicited motor response. By exposing rats to 11 acoustic stimuli of increasing intensity from 65 to $115 \mathrm{~dB}$ SPL in $5 \mathrm{~dB}$ SPL steps ( $20 \mathrm{~ms}$ white noise with $5 \mathrm{~ms}$ rise/fall time, every $60 \mathrm{~s}$ presented on top of white background noise), the startle threshold was determined, as well as the maximum startle reactivity for the three genotypes of rats at the two ages (P38 and P78; (wild-type: 12 males, 10 females; Cntnap $2^{+1-}: 16$ males, 16 females; Cntnap $2^{-1-}: 8$ males, 12 females). For each animal, the peak amplitude of the startle response was recorded at each sound level and the results were averaged across females or males for each genotype (see Fig. 5A).

On days two and three, the rats were acclimated to the startle boxes for $5 \mathrm{~min}$. To determine the impact of Cntnap 2 knock-out on sensory filtering, the rats were then repeatedly presented a startle-eliciting stimulus and the degree that their startle response habituated was compared across the genotypes. Thirty startle stimuli ( $20 \mathrm{~ms}$ white noise at $105 \mathrm{~dB}$ SPL; 5 ms rise/fall time) were presented with a randomly varying intertrial interval (ITI: 12,15 , or $18 \mathrm{~s}$ ) during a continuous background noise ( $60 \mathrm{~dB}$ SPL white noise). Habituation was assessed from the first 8 trials on day two in all three genotypes at both P38 (wild-type: 11 males, 11 females; Cntnap $2^{+/-}: 14$ males, 15 females; Cntnap $2^{-1-}: 12$ males, 14 females) and P78 (wild-type: 12 males; 8 females; Cntnap $2^{+/-}: 15$ males, $16 \mathrm{fe}-$ males; Cntnap $2^{-1-}: 8$ males, 12 females; see Fig. 6 A). A habituation score was calculated for each animal using the following formula:

Habituation score

(maximum startle magnitude trial $7+$ maximum startle magnitude trial 8 )/2 maximumstartle magnitude trial 1

Next, sensorimotor gating was assessed by measuring the amount that each rat's startle response was attenuated (i.e., PPI) when the startle stimulus (pulse) was preceded by a brief, nonstartling stimulus (prepulse). Subsequently to habituation, PPI was assessed as follows: over a total of 50 additional trials, the startle stimulus $(20 \mathrm{~ms}$ white noise at 105 $\mathrm{dB}$ SPL; $5 \mathrm{~ms}$ rise/fall time) was presented alone or following an acoustic 
prepulse stimulus ( $10 \mathrm{~ms}$ white noise at either $75 \mathrm{~dB}$ SPL or $85 \mathrm{~dB}$ SPL; 5 $\mathrm{ms}$ rise/fall time). During a continuous background noise (60 dB SPL white noise), prepulses were presented 30 or $100 \mathrm{~ms}$ (i.e., the interstimulus interval, ISI) before the startle stimulus for maximum PPI (Ison et al., 1973; Graham, 1975; Graham and Murray, 1977; Hoffman and Ison, 1980; Valsamis and Schmid, 2011; Typlt et al., 2013; Pinnock et al., 2015; Zaman et al., 2017). In total, the animals were randomly presented 10 trials of each stimulus type (startle alone; $75 \mathrm{~dB}$ at $30 \mathrm{~ms}$ ISI; $75 \mathrm{~dB}$ at 100 ms ISI, $85 \mathrm{~dB}$ at $30 \mathrm{~ms}$ ISI, and $85 \mathrm{~dB}$ at $100 \mathrm{~ms}$ ISI), with the trials separated by a randomly varying ITIs $(12,15$ or 18 s; see Fig. $7 A)$. The relative percentage of PPI was calculated using the maximum startle amplitudes as follows:

$$
\% P P I=\left(1-\left(\frac{\text { prepulse pulse }}{\text { pulse alone }}\right)\right) \times 100 \%
$$

In addition to measuring changes in startle magnitude to assess PPI, the latency of the startle response was also measured in trials with/without the prepulse as an increased latency to the maximum startle amplitude is indicative of sensorimotor gating (Hoffman and Wible, 1970; Ison et al., 1973). The relative changes in latency were calculated as the time to reach the maximum startle magnitude on startle pulse-alone trials subtracted from that during prepulse trials (i.e., positive values represented an increase in latency on prepulse trials; Lyall et al., 2009; Marriott et al., 2016; see Fig. 8A). The amplitude and latency measures of PPI from days two and three were grouped based on trial type and averaged to obtain a single value for all five prepulse conditions per animal. Ultimately, to assess the developmental changes in sensorimotor gating, PPI was measured at P38 and P78 in the three genotypes (wild-type: 10 males, 9 females; Cntnap2 $2^{+/-}: 15$ males, 16 females; Cntnap $2^{-l-}: 8$ males, 12 females).

Locomotor activity. Rats (wild-type: 12 males, 10 females; Cntnap $2^{+/-}$. 16 males, 16 females; Cntnap2 $2^{-1-}: 8$ males, 12 females) were tested at P38 and P78. Locomotor testing took place on day two at least $1 \mathrm{~h}$ before acoustic startle testing (described above) in a dimly lit room to which the animals were acclimated. Rats were placed in a $20 \mathrm{~cm} \times 20 \mathrm{~cm}$ locomotor box (Versamax) to freely explore for $20 \mathrm{~min}$. Total distance traveled (meters) and velocity (meters/s) were used as measures of hyperactivity and the proportion of time spent in center of the locomotor box was used as an index of anxiety. Locomotor data were tabulated, parsed into $5 \mathrm{~min}$ blocks for each rat, and then averaged for the respective experimental groups.

Immunohistochemistry. Wild-type male animals at ages P28 $(n=3)$, P42 $(n=3)$, and P70 $(n=3)$ were killed by intravenous injections of an overdose of sodium pentobarbital (Euthanyl Forte; Bimeda-MTC Animal Health) and intracardially perfused with $0.9 \%$ saline followed by $4 \%$ paraformaldehyde (PFA). The brains were harvested, postfixed in PFA for $1 \mathrm{~h}$, and stored in $30 \%$ sucrose until sliced into $40 \mu \mathrm{m}$ slices using a freezing microtome (KS34S; Thermo Fisher Scientific). Slices were divided into 4 parallel series and stored at $-20^{\circ} \mathrm{C}$ in cryoprotectant solution (30\% sucrose, $30 \%$ ethylene glycol, and $5 \%$ of $0.01 \%$ sodium azide in $0.1 \mathrm{M} \mathrm{PB}$ ). To assess the expression of CASPR2, the Cntnap2 gene protein product, immunolabeling was performed on free-floating tissue sections. Before free-floating immunohistochemistry, as well as in between all incubations with antibodies, all slices were thoroughly rinsed in $0.1 \mathrm{M}$ PBS. Slices were pretreated with a $1 \% \mathrm{H}_{2} \mathrm{O}_{2}$ in $0.1 \mathrm{M}$ PBS for $10 \mathrm{~min}$, then blocked for $1 \mathrm{~h}$ in $10 \%$ normal goat serum (NGS) (Thermo Fisher Scientific catalog \#50197Z) before incubation with primary antibody overnight (anti-Caspr2, clone K67/25(1:100, mouse; Millipore) in a solution of $0.1 \mathrm{M}$ PBS with $1 \%$ NGS. Next, sections were incubated with biotinylated secondary antibody (1:500; anti-mouse, vector, AB_2336171; MJS BioLynx) in 1\% NGS solution for $1 \mathrm{~h}$ at room temperature. Sections were then processed using avidin-biotin complex solution in PBS (1 h at room temperature, 1:1000; Vectastain Elite ABC Kit, pk 6100; $A B \_2336819$ ) and labeling was visualized using 3,3'diaminobenzidine tetrahydrochloride (DAB) solution $\left(0.04 \% \mathrm{H}_{2} \mathrm{O}_{2}, 0.2\right.$ $\mathrm{mg} / \mathrm{ml} \mathrm{DAB}$; D4293, Sigma-Aldrich). Tissue was then mounted onto positively charged glass slides, dried overnight, dehydrated in increasing alcohol, cleared in xylene, and coverslipped with DPX mounting me- dium (Millipore, HX55746679). Imaging was performed using a Nikon Eclipse Ni-U upright microscope with a DS-Qi2 high definition color camera and imaging software NIS Elements Color Camera (Nikon).

Experimental design and statistical analysis. The main objective of the present study was to investigate the developmental trajectory of auditory deficits in electrophysiological and behavioral measures of brainstem function in juvenile, adolescent, and adult Cntnap2 homozygous $\left(\right.$ Cntnap $\left.2^{-1-}\right)$ and heterozygous knock-out (Cntnap2 ${ }^{+/-}$) and wildtype rats of both sexes. Therefore, electrophysiological and behavioral testing was performed on at least seven rats from each genotype and sex at P28, P42, and P70 (electrophysiology) or at P38 and P78 (behavior). Various types of split-plot randomized complete block designs with repeated measures were used (Altman and Krzywinski, 2015). To compare differences between genotypes across age for all experiments, general linear model repeated-measures analyses (three- or four4-way factorial design, with multiple within-subject and between-subject variables) were performed using a univariate model approach. More specifically, age (P28, P42 and P70; P38 and P78) and, in some experiments, stimulus type (various levels) were included as within-subject factors, whereas genotype (Cntnap $2^{-1-}$, Cntnap $2^{+/-}$, and wild-type) and sex (male and female) represented the between-subject factors. The Mauchly test was used to determine whether the data violated the sphericity assumption. In the case of a violation, the degrees of freedom were corrected using the Greenhouse-Geisser (if $\varepsilon<0.75$ ) or the Huynh-Feldt method (if $\varepsilon>$ 0.75 ). Main effects and interactions were assessed, followed by post hoc simple main effect analysis for the overall effect of genotype and $t$ tests using the Bonferroni correction to further investigate specific differences between wild-type animals and either Cntnap $2^{-1-}$ or Cntnap $2^{+/-}$rats at a given age. Differences were considered statistically significant when $p$-values (adjusted) were smaller than $\alpha=0.05$. In all experiments, interactions involving genotype or a main effect of genotype were of utmost interest. For most measures collected, heterozygous rats did not differ significantly from wild-types, so they were not included in figures. Data analyses were performed with Microsoft Excel 2010 and graphical display was completed with GraphPad Prism 6.01 and Inkscape 0.92.1 software. SAS/STAT version 9.4 was used for statistical analysis (SAS Institute).

\section{Results}

\section{Animals}

Before the ABR testing, rats were weighed and the differences in body mass was analyzed (age $\times$ sex $\times$ genotype). A three-way interaction was observed $\left(F_{(2.9,81.3}=3.92, p=0.005\right)$, and a simple main effect analysis for genotype revealed that only males' body mass differed between genotypes at $\mathrm{P} 42\left(F_{(2,110)}=18.3, p<\right.$ $0.0001, \eta p 2=0.25)$ and P70 $\left(F_{(2,110)}=39.0, p<0.0001, \eta p 2=\right.$ $0.42)$. Ultimately, post hoc $t$ tests revealed that Cntnap $2^{-/-}$males had a lower body mass than wild-types in adolescence (P42, wildtype: $232.2 \pm 3.17 \mathrm{~g}$; Cntnap2 $\left.{ }^{-1-}: 205.6 \pm 3.47 \mathrm{~g} ; p<0.0001\right)$ and adulthood (P70, wild-type: $447.1 \pm 3.17 \mathrm{~g}$; Cntnap $^{-1-}$ : $412.5 \pm 3.47 \mathrm{~g} ; p<0.0001)$. In contrast, the body mass of Cntnap $2^{+1-}$ rats did not differ from wild-types (data not shown).

\section{ABRs}

\section{Hearing thresholds}

To determine whether hearing sensitivity throughout development differed between genotypes, the ABR thresholds to a click, 4 $\mathrm{kHz}$, and $20 \mathrm{kHz}$ stimulus were compared at P28, P42, and P70 (age $X \operatorname{sex} \times$ sound type $\times$ genotype; Fig. 2$)$. This analysis revealed a significant interaction of sound type $\times$ genotype $\left(F_{(4,110)}\right.$ $=3.41, p=0.011)$, a main effect of age $\left(F_{(2,110)}=3.25, p=\right.$ $0.043)$, and no effect of $\operatorname{sex}\left(F_{(1,55)}=1.07, p=0.31\right)$. Surprisingly, post hoc tests revealed that heterozygous $\left(\right.$ Cntnap $\left.2^{+/-}\right)$rats had a slightly lower hearing threshold (i.e., better hearing sensitivity) to the $20 \mathrm{kHz}$ stimulus in adulthood compared with wild-types $(p<$ 0.001; data not shown). In contrast, the ABR thresholds for the three stimuli (i.e., click, $4 \mathrm{kHz}$, and $20 \mathrm{kHz}$ ) were not significantly 
P28

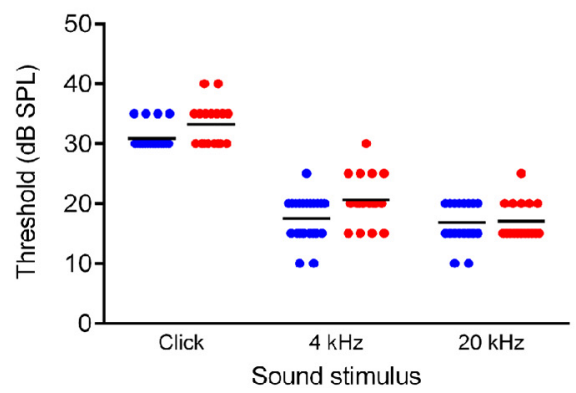

P42

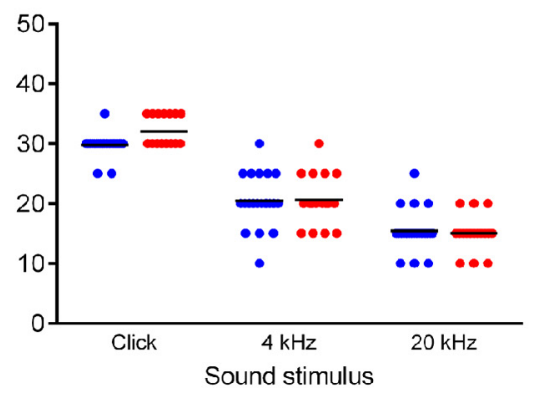

P70

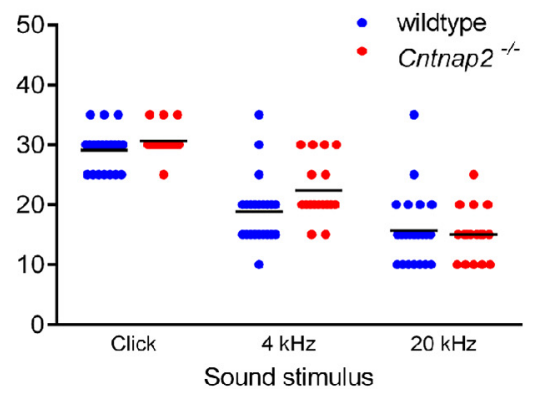

Figure 2. Cntnap2 ${ }^{-1-}$ rats have typical hearing thresholds. Scatter plot of click, $4 \mathrm{kHz}$, and $20 \mathrm{kHz}$ stimulus thresholds for individual wild-type (blue) and (ntnap2 ${ }^{-/-}$(red) animals as juveniles (P28), adolescents (P42), and adults (P70). Mean is represented by a horizontal line. ABR thresholds showed no differences between wild-type and knockout animals for all stimuli tested.

A

P28

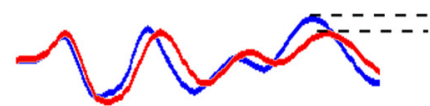

P42

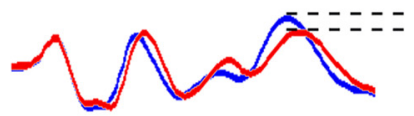

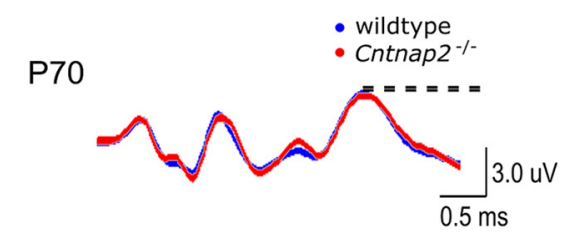

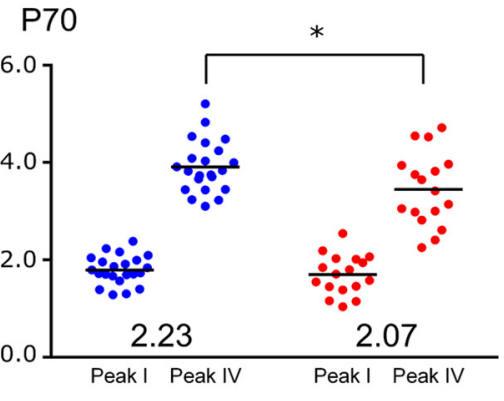

Figure 3. Cntnap $2^{-1-}$ rats exhibit a region-specific reduction in neural responsivity in the auditory brainstem across development. $\boldsymbol{A}$, Raw averaged $A B R$ waveforms of wild-type (blue) and Cntnap2 $^{-I-}$ (red) animals to a $90 \mathrm{~dB}$ click stimulus. Dashed lines depict the difference in wave IV amplitude between genotypes. $\boldsymbol{B}$, Scatter plot of absolute peak amplitudes of waves I and IV of the evoked response at P28, P42, and P70. Individual data are plotted and means are represented by a horizontal line. (ntnap2 ${ }^{-1-}$ rats show a persistent reduction in the amplitude of wave IV representing activity of neurons in the lateral lemniscus terminating at the inferior colliculus. The peak IV:I ratio is presented above the $x$-axis to provide an indication of central gain change across age, illustrating the near recovery of Cntnap2 $2^{-1-}$ rats wave IV amplitude through development. Asterisks indicate $p<0.05$.

different between Cntnap2 $2^{-1-}$ rats versus wild-types at the three age groups tested (P28, P42, and P70; Fig. 2), indicating that the homozygous deletion of Cntnap2 did not affect hearing levels throughout development.

\section{Peak amplitudes and latencies}

The rodent ABR consists of four prominent waves, which are thought to represent synchronized neural activity in the auditory nerve, cochlear nucleus, superior olivary complex, and lateral lemniscus (Church and Kaltenbach, 1993; Popelar et al., 2008; Alvarado et al., 2012). In humans, the ABR waves approximating the auditory nerve (wave I), cochlear nucleus (wave III), and lateral lemniscus (wave V), corresponding to the rat waves I, II, and IV, are of importance when studying individuals on the autism spectrum (Wong and Wong, 1991; Rosenhall et al., 2003; Kwon et al., 2007; Tas et al., 2007; Fujikawa-Brooks et al., 2010; Magliaro et al., 2010; Gonçalves et al., 2011; Roth et al., 2012; Miron et al., 2016). Therefore, using data derived from the $90 \mathrm{~dB}$ SPL click stimulus, we analyzed the peak amplitude of waves I and IV (age $X$ sex $\times$ peak number $\times$ genotype), absolute latency of waves I through IV (age $\times$ sex $\times$ peak number $\times$ genotype), and interpeak latencies (IPLs) between waves I and II (I-II IPL) as well as II and IV (II-IV IPL, age $\times$ sex $\times$ genotype). In addition, wave III peak amplitudes were assessed because they visually appeared to differ between genotypes.

When comparing neural response of $\mathrm{ABR}$ waves I and IV, a 3 -way interaction was found between age $\times$ peak number $\times$ genotype $\left(F_{(4,110)}=5.76, p=0.0003\right)$, suggesting differential central gain changes over development between the genotypes. A main effect of sex $\left(F_{(1,55)}=9.44, p=0.003\right)$ was also found. Subsequently, a significant genotype $\times$ age interaction was found for both peak I and IV amplitude (peak I: $F_{(8,110)}=15.5, p<$ $0.0001, \eta p 2=0.53$; peak IV: $F_{(8,110)}=40.5, p<0.0001, \eta p 2=$ $0.75)$. Taken further, the simple main effect of genotype followed by post hoc $t$ tests revealed the effect of Cntnap2 on ABR peak amplitudes throughout development. Indeed, the wave IV peak amplitudes, but not wave I peak amplitudes, were smaller in Cntnap $2^{-1-}$ rats compared with wild-types at all ages (P28: $p<$ 0.0001, P42: $p<0.0001, \mathrm{P} 70: p=0.023$; Fig. 3$)$. This reduction of the wave IV peak amplitude in the homozygous knock-out rats was not sex dependent because there was no genotype $X$ sex interaction $\left(F_{(2,55)}=1.04, p=0.36\right)$. Interestingly, this reduction of wave IV peak amplitude in the Cntnap $2^{-1-}$ rats decreased as they aged, as evidenced by the smaller effect size found in adults $\left(\mathrm{P} 70: F_{(2,110)}=13.2, p<0.0001, \eta p 2=0.19\right)$ compared with 
Table 1. Statistical table for ABR wave III peak amplitudes and corrected post hoct test

\begin{tabular}{llllc}
\hline Genotype & Age & Mean $(\mu \mathrm{V})$ & SEM $(\mu \mathrm{V})$ & $p$-value \\
\hline Wild-type & 28 & 0.58 & 0.065 & - \\
Cntnap2 $^{+1-}$ & 28 & 1.21 & 0.065 & $<0.0001$ \\
Cntnap2 $^{-1-}$ & 28 & 1.35 & 0.075 & $<0.0001$ \\
Wild-type $^{-1}$ & 42 & 0.10 & 0.065 & - \\
Cntnap2 $^{+/-}$ & 42 & 0.46 & 0.065 & 0.008 \\
Cntnap2 $^{-1-}$ & 42 & 0.91 & 0.075 & $<0.0001$ \\
Wild-type $^{-1-}$ & 70 & -0.33 & 0.065 & - \\
Cntnap2 $^{+/-}$ & 70 & -0.21 & 0.065 & - \\
Cntnap2 $^{-/-}$ & 70 & 0.18 & 0.075 & $<0.0001$ \\
\hline
\end{tabular}

Amplitudes are presented in microvolts relative to baseline. $t$ test for a given age compare either the heterozygous knockout or homozygous knockout animals wotj wild-types. Heterozygous $\left(n\right.$ tnap $^{+/-}$are different from wildtypes in young ages, but not in adulthood, whereas differences from wild-types persist in homozygous Cntnap2 $2^{-\prime-}$, suggesting a potential gene-dose effect.

adolescents $\left(\mathrm{P} 42: F_{(2,110)}=37.7, p<0.0001, \eta p 2=0.41\right)$ and juveniles $\left(\mathrm{P} 28: F_{(2,110)}=72.5, p<0.0001, \eta p 2=0.57\right)$. This lower genotype effect observed with age was also reflected in the ratio of peak IV/peak I amplitude, where the ratio in the Cntnap $2^{-1-}$ rats approached that of the wild-types in adulthood (Fig. 3), indicating a normalization of ABR amplitudes upon adulthood. ABR peak amplitudes in Cntnap $2^{+/-}$rats did not differ from the wild-types (data not shown).

Though the wave representing the superior olive is not often assessed in human ASD literature, we observed wave III peak amplitude differences and therefore included them in our analysis. A significant genotype $\times$ age interaction was found $\left(F_{(4,110)}=\right.$ $4.38, p=0.003)$, with no effect of $\operatorname{sex}\left(\mathrm{F}_{1,55}=0.46, p=0.5\right)$. The simple main effect of genotype followed by post hoc $t$ tests (Table 1) revealed that the loss of Cntnap2 affected peak III amplitudes throughout development $\left(\mathrm{P} 28: F_{(2,110)}=36.8, p<0.0001, \eta p 2=\right.$ $0.40 ; \mathrm{P} 42: F_{(2,110)}=32.7, p<0.0001, \eta p 2=0.37 ; \mathrm{P} 70: F_{(2,110)}=$ 14.3, $p<0.0001, \eta p 2=0.21)$.

In addition to the amplitude of the ABR waves, the latency to reach each of the prominent peaks was analyzed (age $\times$ sex $\times$ peak number $\times$ genotype). We observed a genotype effect on peak latency that was dependent on both age and peak number (three-way interaction between peak $\times$ age $\times$ genotype; $F_{(6.5,181)}$ $=5.52, p<0.0001)$, but there was no main effect of $\operatorname{sex}\left(F_{(1,55)}=\right.$ $0.25, p=0.622$ ). As evidenced with the effect size calculations, the influence of genotype on the peak latencies appeared to be compounded in the ABR trace such that the later waves showed greater and more persistent slowing across age than the earlier waves (age $\times$ genotype interaction, peak I: $F_{(8,330)}=11.4, p<$ $0.0001, \eta p 2=0.22$; peak II: $F_{(8,330)}=74.6, p<0.0001, \eta p 2=$ 0.64; peak III: $F_{(8,330)}=209.8, p<0.0001, \eta p 2=0.84$; peak IV: $\left.F_{(8,330)}=338.6, p<0.0001, \eta p 2=0.89\right)$. Put simply, the genotype effect on latency was most prominent in young animals at the later-occurring peaks and this effect lessened with age (Table 2).

As shown in Figure 4, $A$ and $B$, post hoc $t$ tests revealed that Cntnap $2^{-1-}$ rats in particular had increased peak latencies compared with wild-types when young (peak II, P28: $p<0.0001$; peak II, P42: $p=0.02$; peak III, P28: $p<0.0001$; peak III, P42: $p<$ 0.0001; peak IV, P28: $p<0.0001$; peak IV, P42: $p<0.0001$ ), which disappeared upon maturation so that there were no longer any latency differences in adulthood. Finally, this delayed maturation of the speed of neurotransmission throughout the auditory brainstem was only observed in the homozygous knock-out rats, ABR peak latencies were not increased in the Cntnap2 $2^{+/-}$ rats. In fact, compared with wild-types, the Cntnap $2^{+/-}$rats
Table 2. Statistical table for the simple main effect of genotype on ABR peak latency for a given peak and age

\begin{tabular}{llccc}
\hline Peak & Age & F-statistic & $p$-value & Effect size \\
\hline 1 & 28 & 4.42 & 0.010 & 0.03 \\
& 42 & 2.41 & 0.090 & - \\
& 70 & 6.55 & 0.002 & 0.04 \\
2 & 28 & 178.25 & $<0.0001$ & 0.32 \\
& 42 & 9.09 & 0.0001 & 0.05 \\
& 70 & 3.51 & 0.03 & 0.02 \\
3 & 28 & 173.63 & $<0.0001$ & 0.51 \\
& 42 & 43.95 & $<0.0001$ & 0.21 \\
& 70 & 4.64 & 0.010 & 0.03 \\
4 & 28 & 262.98 & $<0.0001$ & 0.61 \\
& 42 & 44.43 & $<0.0001$ & 0.21 \\
& 70 & 1.85 & 0.160 & - \\
\hline
\end{tabular}

Effect sizes are greater in the later peaks and overall decrease with age. Degrees of freedom: 2; error degrees of freedom: 330 .

showed modestly shorter latencies (i.e., faster neurotransmission) for ABR waves III and IV as juveniles (P28, $p<0.0001$; data not shown).

The effect of the loss of Cntnap2 on the IPLs between waves I-II and II-IV were examined separately (age $\times$ sex $\times$ genotype). Age was found to influence the effect of genotype $\left(F_{(4,110)}=5.40\right.$, $p=0.0005)$ such that the strength of the genotype effect on I-II IPL decreased with age $\left(\mathrm{P} 28: F_{(2,110)}=67.0, p<0.0001, \eta p 2=0.55 ; \mathrm{P} 42\right.$ : $F_{(2,110)}=23.9, p<0.0001, \eta p 2=0.30$; P70: $F_{(2,110)}=17.0, p<$ $0.0001, \eta p 2=0.24)$ with no main effect of $\operatorname{sex}\left(F_{(1,55)}=3.46, p=\right.$ 0.07). Whereas the Cntnap $2^{+/-}$rats were again not different from wild-types (data not shown), the Cntnap $2^{-1-}$ rats had a longer wave I-II IPL than wild-types at all ages (P28: $p<0.0001$; P42: $p<0.0001$; P70: $p<0.0001$; Fig. $4 C)$. Similarly, an age $\times$ genotype interaction was found for IPL II-IV $\left(F_{(4,110)}=6.45, p=\right.$ $0.0001)$, with post hoc tests revealing that Cntnap2 ${ }^{-1-}$ animals had a significantly longer IPL at only P28 ( $p=0.0096$; Fig. $4 D)$. Interestingly, Cntnap $2^{+1-}$ animals had a slightly shorter IPL than wild-types at P28 ( $p=0.002$; data not shown $)$.

\section{Acoustic reactivity}

To assess acoustic reactivity throughout development, startle response magnitudes to a series of startle pulses of increasing volume (65-115 dB in $5 \mathrm{~dB}$ SPL increments) were measured and analyzed (age $\times$ sex $\times$ startle pulse level $\times$ genotype). All of the three-way interactions involving genotype were found to be significant (age $\times$ startle pulse level $\times$ genotype: $F_{(13.37,454.44)}=$ $2.35, p=0.004$; sex $\times$ startle pulse level $\times$ genotype: $F_{(10.20,373.73)}$ $=2.35, p=0.008$; age $\times$ sex $\times$ genotype: $F_{(1,68)}=3.23, p=$ $0.046)$. Because an animal's body mass can affect its startle response magnitude (and body mass was found to vary with age and sex in the present study), we subsequently analyzed the simple main effect of genotype for males and females at both ages P38 and P78. Collapsing across startle pulse level ultimately revealed genotype differences in adulthood for both females $\left(F_{(2,68)}=\right.$ 8.46, $p=0.0005, \eta p 2=0.20)$ and males $\left(F_{(2,68)}=27.4, p<\right.$ $0.0001, \eta p 2=0.45$; Fig. $5 B)$. To summarize the results, Cntnap $2^{-1-}$ rats of both sexes showed increased acoustic reactivity compared with wild-types (female: $p=0.007$; male: $p<$ 0.0001 ), which could be visualized as a leftward shift in the relation between startle response magnitude and intensity (Fig. 5). Interestingly, this increased acoustic reactivity in the Cntnap $2^{-1-}$ rats became more robust as animals aged, as evidenced by the increased effect size of the startle pulse level $\times$ genotype interaction found in adulthood compared with adolescence for both 


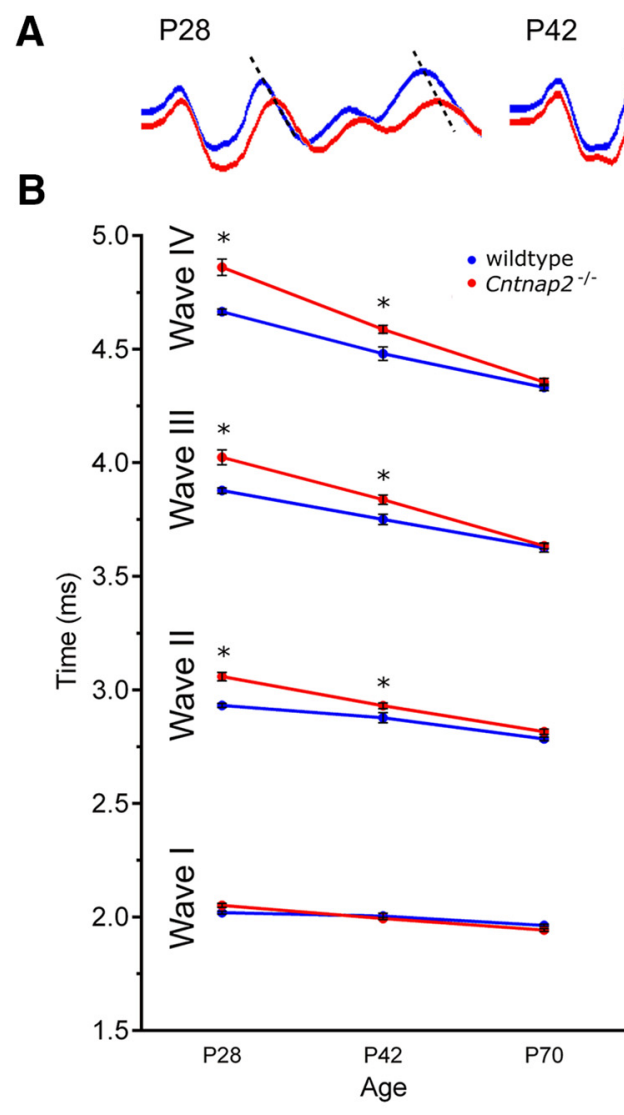

P42

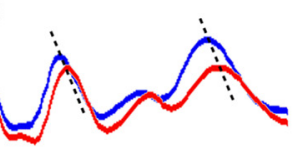

P70

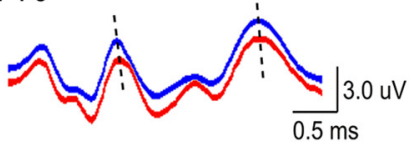

C Inter-peak latency I - II

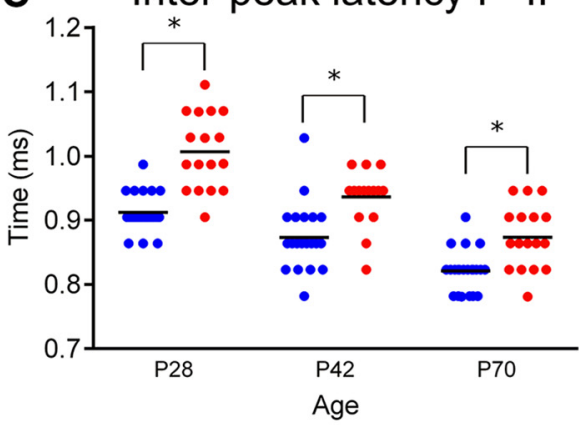

D Inter-peak latency II - IV

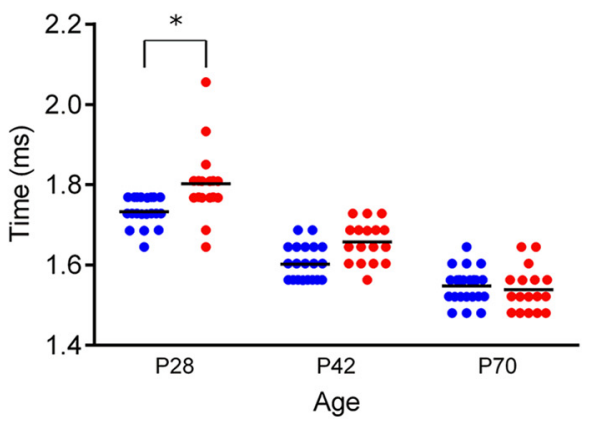

Figure 4. Cntnap2 ${ }^{-1-}$ rats exhibit reduced brainstem neurotransmission speed when young, which matures by adulthood. $A$, Raw averaged traces of the ABR waveform to a $90 \mathrm{~dB}$ SPL click stimulus for wild-type (blue) and Cntnap2 ${ }^{-1-}$ (red) animals at P28, P42, and P70. Dashed lines highlight the delay in response latency. B, Averaged absolute peak latency from stimulus onset for

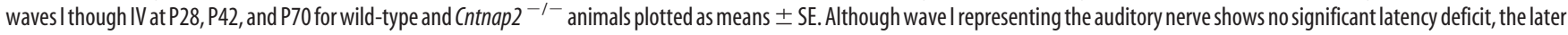
occurring waves II, III, and IV show a compounding delay in response time which normalizes with age. C, $\mathbf{D}$, Individual data are plotted and mean is represented by a horizontal line for IPL I-II and IPL II-IV. Cntnap2 ${ }^{-I-}$ rats show a prolonged IPL I-II that only partially recovers, whereas the IPL II-IV delay fully recovers with age. Asterisks indicate $p<0.05$.

females (P72: $F_{(32,680)}=37.7, p<0.0001, \eta p 2=0.64 ; \mathrm{P} 38$ : $\left.F_{(32,680)}=16.0, p<0.0001, \eta p 2=0.43\right)$ and males $\left(\mathrm{P} 72: F_{(32,680)}\right.$ $=58.3, p<0.0001, \eta p 2=0.73$; P38: $F_{(32,680)}=17.6, p<0.0001$, $\eta p 2=0.45)$. Most notably, adult male Cntnap $2^{-1-}$ rats showed a considerable increase in acoustic reactivity compared with wildtypes at moderately loud sound intensities of $85 \mathrm{~dB}$ SPL $(p<$ $0.0001), 90 \mathrm{~dB}$ SPL $(p<0.0001)$, and $95 \mathrm{~dB}$ SPL $(p=0.019$; Fig. $5 B)$. Cntnap $2^{+/-}$rats did not differ from wild-types in acoustic reactivity (data not shown).

\section{Habituation}

To assess sensory filtering, short-term habituation of the startle response was measured across the first eight startle trials of the test day and analyzed (age $\times$ sex $\times$ genotype). A main effect of genotype was found at P38 $\left(F_{(2,70)}=5.25, p=0.008\right)$, in which adolescent Cntnap $2^{-1-}$ rats habituated significantly less than wild-type animals ( $p=0.011$; Fig. $6 B$ ). The extent of short-term habituation was further quantified by normalizing the average of the last two startle responses of each animal to its initial startle response to calculate a habituation score. A main effect of genotype was found for the habituation score $\left(F_{(2,70)}=5.50, p=\right.$ $0.006)$, with post hoc $t$ tests revealing a significant difference only between Cntnap2 $2^{-/-}$and wild-type rats at P38 ( $p=0.012$; Fig. $6 C)$. No differences were found between genotypes at P78 in habituation of startle magnitude across trials $\left(F_{(2,64)}=0.83, p=\right.$ 0.441 ; Fig. $6 B)$ or in the habituation score $\left(F_{(2,64)}=0.09, p=\right.$
0.911; Fig. 6C). Therefore, sensory filtering was only impaired in young Cntnap2 $2^{-1-}$ rats.

\section{PPI}

The effect of Cntnap2 knock-out on sensorimotor gating throughout development was assessed using PPI of startle. The relative amount of PPI (\%PPI) elicited by two prepulse stimulus levels at two different ISIs was analyzed (prepulse type $\times$ age $\times$ genotype $X$ sex). This analysis revealed a four-way interaction $\left(F_{(5.3,169.6)}=2.24, p=0.049\right)$, with genotype interacting with prepulse type and age, but not sex (prepulse type $\times$ genotype: $F_{(4.85,155.06)}=9.73, p<0.0001$; age $\times$ genotype: $F_{(2,64)}=15.4$, $p<0.0001$; genotype $\times$ sex: $\left.F_{(2,64)}=0.80, p=0.453\right)$. These significant interactions were further explored by collapsing across sex to examine the effect of genotype across age for the four different prepulse types (i.e., $75 \mathrm{~dB}$ at $30 \mathrm{~ms}$ ISI, $75 \mathrm{~dB}$ at $100 \mathrm{~ms}$ ISI, $85 \mathrm{~dB}$ at $30 \mathrm{~ms}$ ISI, and $85 \mathrm{~dB}$ at $100 \mathrm{~ms} \mathrm{ISI)}$. Using analyses of simple main effects, it was found that the genotypes differed for the majority of the prepulse types used in the present study, with increased effect sizes in adulthood (Table 3). Ultimately, post hoc $t$ tests confirmed that the Cntnap $2^{-/-}$rats showed a significant PPI deficit for the $75 \mathrm{~dB}, 100 \mathrm{~ms}$ condition early during development (P38: $p<0.0001)$ and that this deficit extended to all prepulse conditions by adulthood (P78: $75 \mathrm{~dB}$ SPL, $30 \mathrm{~ms}: p<$ 0.0001; 75 dB SPL, 100 ms: $p<0.0001$; 85 dB SPL, $30 \mathrm{~ms}: p=$ 0.0026; 85 dB SPL, 100 ms: $p<0.0001$; Fig. 7C). Therefore, the 
A
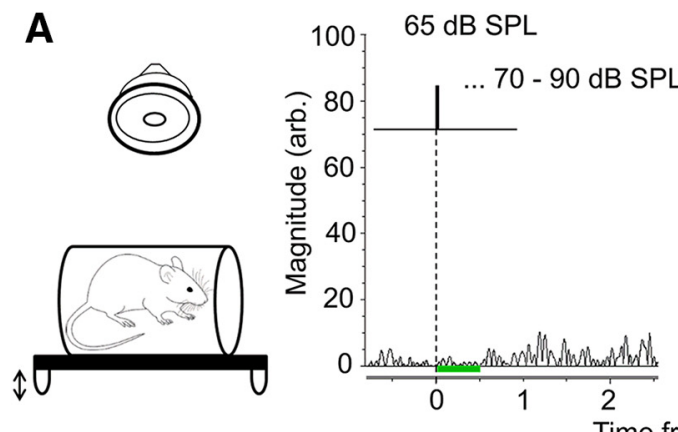

$95 \mathrm{~dB}$ SPL

$115 \mathrm{~dB}$ SPL

B
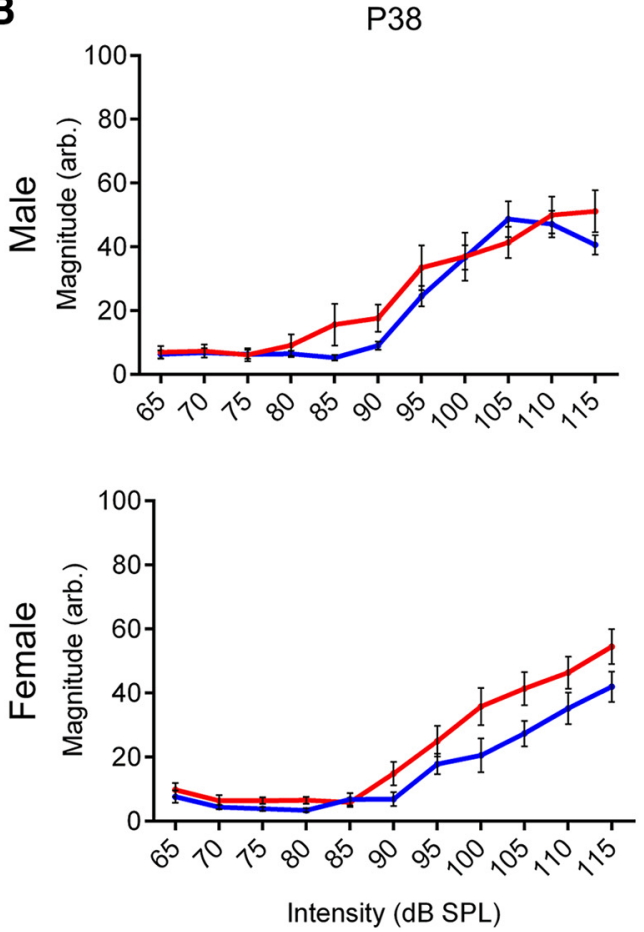
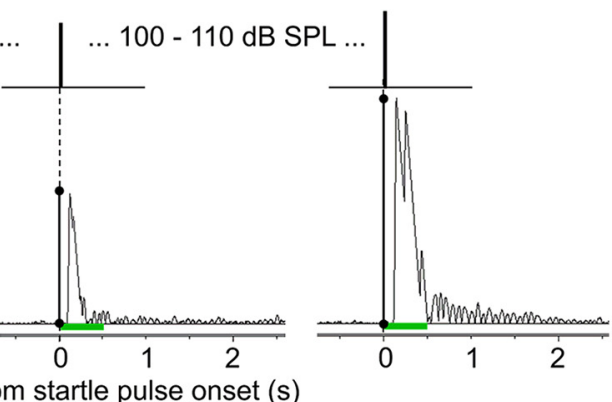

P78
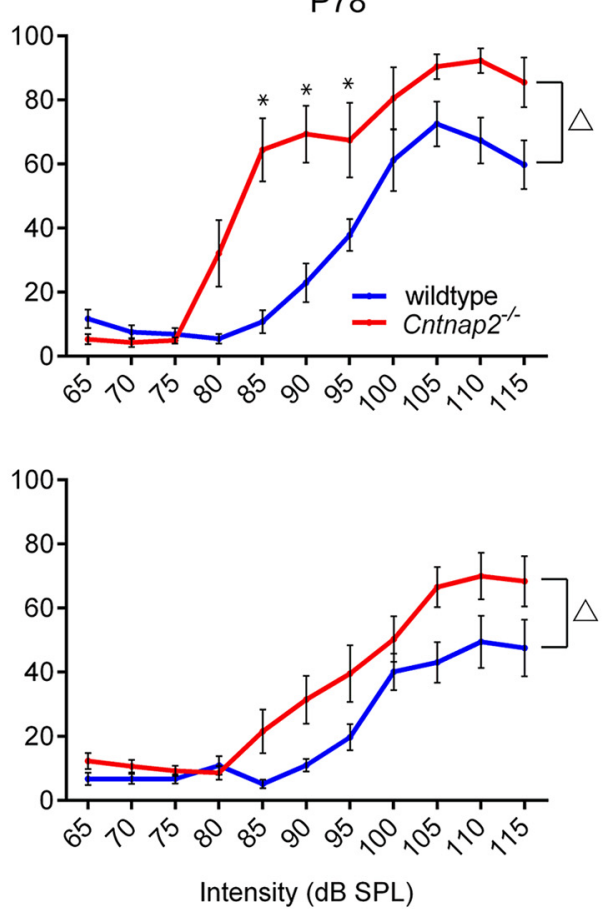

Figure 5. Acoustic reactivity is increased in adult $\left(n t n a p 2^{-1-}\right.$ rats compared with wild-types. A, Positioning of rat in startle tube apparatus set on a movement sensitive platform with an overhead speaker emitting the acoustic startle stimulus (left). Right diagram depicts three representative raw acoustic startle stimuli (65, 95, and $115 \mathrm{~dB} \mathrm{SPL}$ ) and corresponding ASR traces from an adult male wild-type rat as measured by the STARTLE software module. Black bars denote the ASR magnitude and green bars indicate the $500 \mathrm{~ms}$ ASR recording window. $\boldsymbol{B}$, Male (top) and female (bottom) animals' startle response magnitude to decibel levels from 65 to $115 \mathrm{~dB} \mathrm{SPL}$ in wild-type (blue) and Cntnap2 ${ }^{-1-}$ (red) animals at P38 (left) and P78 (right) plotted as means \pm SE. Young Cntnap2 $^{-/-}$animals are no different from wild-types; however, a significant acoustic startle reactivity deficit appears in adult males and females. A leftward shift of the input/output curve is observed in Cntnap2 ${ }^{-1-}$ rats, which is indicative of increased reactivity to the acoustic stimuli and is especially apparent at the 85, 90, and $95 \mathrm{~dB} \mathrm{SPL} \mathrm{startle} \mathrm{pulses} \mathrm{in} \mathrm{adult}$ (ntnap $^{-1-}$ males. Asterisks indicate $p<0.05$.

homozygous knock-out of Cntnap2 impaired sensorimotor gating as assessed by the relative level of PPI during youth and this impairment worsened with age. Cntnap $2^{+1-}$ rats were largely no different from wild-types and only showed slightly increased PPI in adulthood at the $85 \mathrm{~dB}, 100 \mathrm{~ms}$ prepulse condition $(p=$ $0.018)$.

As a complement to the assessment of PPI, we also examined the change in latency to the maximum startle response in trials with versus without a prepulse. Although there was no interaction of all four factors (prepulse type $\times$ age $\times$ genotype $\times$ sex), there was a significant three-way interaction between prepulse type, age and genotype $\left(F_{(6,192)}=2.47, p=0.025\right)$. As shown in Table 4, there was a simple main effect of genotype for most of the prepulse types; however, there were no clear trends in the effect size across age. Overall, post hoc tests confirmed that, compared with wild-types, Cntnap $2^{-1-}$ rats' startle latencies did not increase in trials that included a prepulse, findings indicative of impaired sensorimotor gating. This lack of latency increase was apparent during the $75 \mathrm{~dB}, 30 \mathrm{~ms}$ prepulse trials in the young Cntnap $2^{-1-}$ rats $(p=0.001)$. Moreover, a persistent deficit was observed in both $85 \mathrm{~dB}$ conditions in the young and adult Cntnap $^{-1-}$ rats (85 dB SPL, $30 \mathrm{~ms}$, P38: $p<0.0001 ; 85 \mathrm{~dB}$ SPL, $30 \mathrm{~ms}$, P78: $p=0.018$; $85 \mathrm{~dB}$ SPL, $100 \mathrm{~ms}$, P38: $p<0.0001 ; 85 \mathrm{~dB}$ SPL, 100 ms, P78: $p<0.0001$; Fig. 8C). Heterozygous $\left(\right.$ Cntnap $\left.2^{+/-}\right)$rats were not different from wild-types in any condition (data not shown).

\section{Locomotor activity}

To evaluate the effect of Cntnap2 on locomotion and anxiety-like behavior, locomotor activity was evaluated in $5 \mathrm{~min}$ time bins for a total of $20 \mathrm{~min}$. Distance traveled and velocity were used as measures of activity (time bin $\times$ age $\times$ genotype $\times$ sex). Although there were no 4 - or 3-way interactions found involving the distance traveled, a significant interaction existed between genotype $\times$ time bin $\left(F_{(4.07,138.5)}=5.51, p=0.0003\right)$, as well as a main effect of age $\left(F_{(1,68)}=4.36, p=0.041\right)$. To further explore 
this interaction, data were collapsed across sex and the effect of genotype was considered with respect to time bin and age. Therefore, a simple main effect analysis revealed an effect of genotype, but only in the first time bin at both ages (P38: $F_{(2,204)}=32.3, p<0.0001, \eta p 2=0.24$; P78: $F_{(2,204)}=27.7, p<0.0001, \eta p 2=$ $0.21)$. Ultimately, post hoc tests showed that Cntnap $2^{-1-}$ rats initially traveled a significantly greater distance in the first time bin during adolescence (P38: $p<$ $0.0001)$ and adulthood (P72: $p<0.0001$; Fig. 9A), similar to previous findings in this knock-out rat (Thomas et al., 2016). No differences were found between Cntnap2 $2^{+/-}$and wild-type rats (data not shown).

Similar to the aforementioned results, a significant interaction between genotype and time bin was found for the velocity of movement during the locomotor testing $\left(F_{(4.08,139)}=5.55, p=0.0003\right)$, as well as a main effect of age $\left(F_{(1,68)}=4.50\right.$, $p=0.038)$. Upon further analysis, there was an effect of genotype in the first time bin at both P38 $\left(F_{(2,204)}=32.2, p<\right.$ $0.0001, \eta p 2=0.24)$ and $\mathrm{P} 78\left(F_{(2,204)}=\right.$ $27.4, p<0.0001, \eta p 2=0.21)$ and also in the second time bin at $\mathrm{P} 78\left(F_{(2,204)}=8.06\right.$, $p=0.0004, \eta p 2=0.07)$. Ultimately, post hoc tests showed that Cntnap $2^{-1-}$ rats had a greater movement velocity than wild-types in the first time bin at both P38 (wild-type: $0.046 \pm 0.001 \mathrm{~m} / \mathrm{s}$; Cntnap2 $2^{-l-}: 0.056 \pm 0.001 \mathrm{~m} / \mathrm{s} ; p<$ 0.0001 ) and P78 (wild-type: $0.036 \pm 0.001$ $\mathrm{m} / \mathrm{s} ;$ Cntnap2 $^{-/-}: 0.024 \pm 0.001 \mathrm{~m} / \mathrm{s} ; p<$ 0.0001 ; data not shown). There were no differences between Cntnap2 $2^{+/-}$and wild-type rats (data not shown).

The amount of time spent in center of the locomotor box versus the surrounding perimeter (percentage center) was used as a surrogate measure of anxietylike behavior. A main effect of age $\left(F_{(1,68)}\right.$ $=22.90, p<0.0001$ ) was found, with no main effect of genotype or interactions. There was, however, a trend for an interaction between genotype $\times$ time bin $\left(F_{(6,204)}=2.03, p=0.064\right)$. We therefore examined the simple main effect of genotype for young and adult animals in each time bin. In adolescence, the genotypes differed in their spent more time in the center in the last $15 \mathrm{~min}$ and adults in the last $5 \mathrm{~min}$ of the $20 \mathrm{~min}$ testing sessions, although the effects were small (Table 5) and did not reach significance in corrected $t$ tests.

\section{CASPR2 expression}

To establish the presence of CASPR2 in the auditory and startle structures of interest, immunohistochemistry was performed across age in wild-type animals (Fig. 10). At all three ages, CASPR2 staining can be observed in the dorsal cochlear nucleus

B
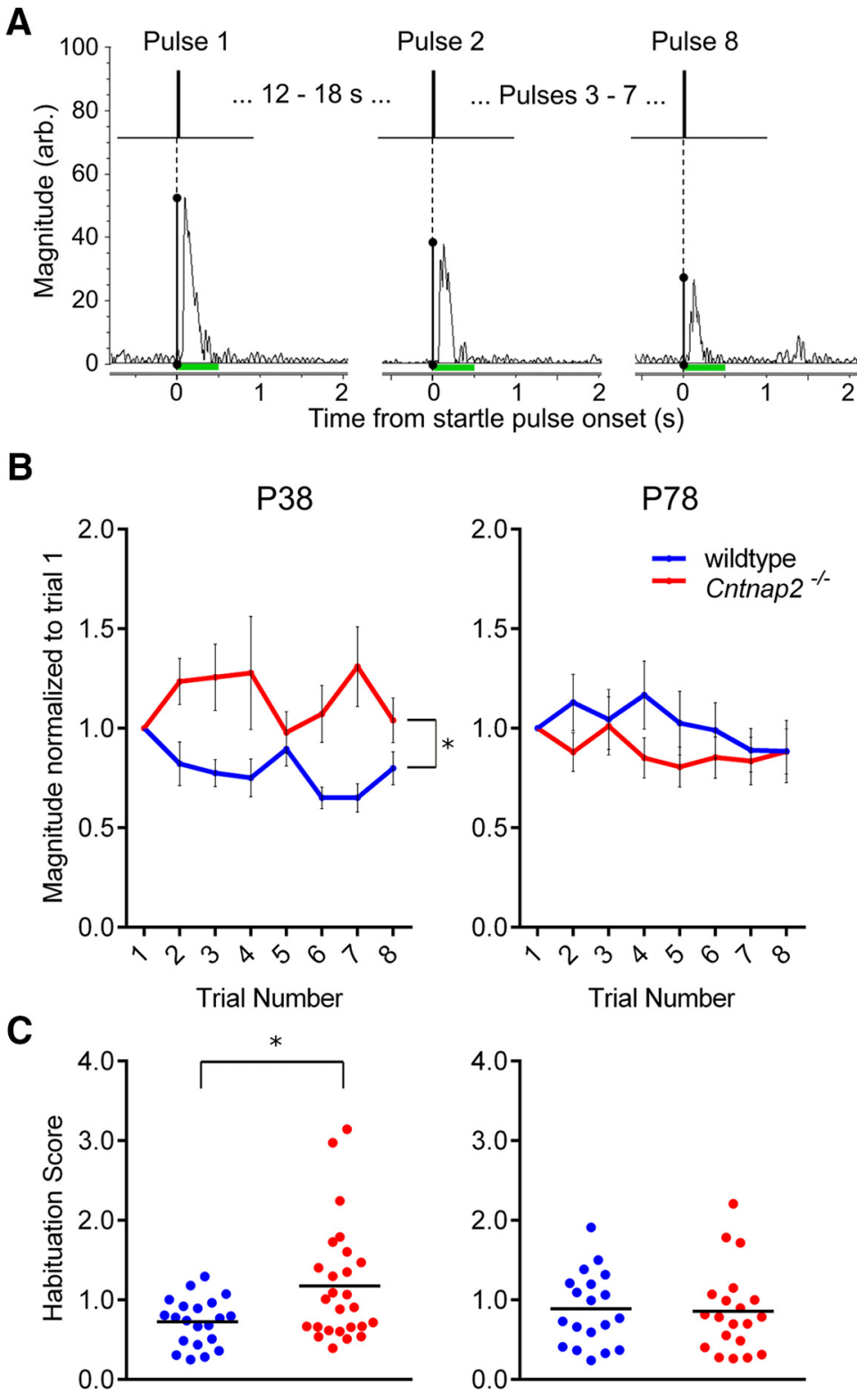

Figure 6. Sensory filtering as measured by short-term habituation of the ASR is perturbed in young knock-out rats. $A$, Representative raw ASR traces from an adult male wild-type rat depicts the decrease in ASR magnitude (black bars) to the repeated presentation of the startle pulse (105 dB SPL) as measured by the STARTLE software module. Green bars indicate the $500 \mathrm{~ms}$ ASR recording window. $\boldsymbol{B}$, Wild-type (blue) and Cntnap2 $^{-1-}$ (red) animals' normalized startle response magnitudes at P38 and P78 across eight subsequent trials. Values $<1.0$ are indicative of habituation of the startle response. Cntnap2 ${ }^{-1-}$ animals show no decline in response magnitude at P38. C, Individual habituation scores, taken as the average of the last two trials divided by that of the first, at P38 and P78 of the respective genotypes are displayed with the horizontal line representing the mean score. A score $<1.0$ is indicative of habituation of the startle response. Cntnap $2^{-1-}$ animals do no habituate across trials compared with wild-type animals during adolescence. Asterisks indicate $p<0.05$.

Table 3. Statistical table for the simple-main effect of genotype on percentage PPI

\begin{tabular}{llccc}
\hline Prepulse type & Age & F-statistic & $p$-value & Effect size \\
\hline $75 \mathrm{~dB} \mathrm{SPL}$ & 38 & 6.65 & 0.002 & 0.06 \\
$30 \mathrm{~ms}$ & 78 & 36.7 & $<0.0001$ & 0.28 \\
$75 \mathrm{~dB} \mathrm{SPL}$ & 38 & 35.0 & $<0.0001$ & 0.27 \\
$100 \mathrm{~ms}$ & 78 & 94.2 & $<0.0001$ & 0.50 \\
$85 \mathrm{~dB} \mathrm{SPL}$ & 38 & 0.29 & 0.752 & - \\
$30 \mathrm{~ms}$ & 78 & 22.2 & $<0.0001$ & 0.19 \\
$85 \mathrm{~dB} \mathrm{SPL}$ & 38 & 3.43 & 0.034 & 0.03 \\
$100 \mathrm{~ms}$ & 78 & 59.6 & $<0.0001$ & 0.38
\end{tabular}

Effect sizes for each prepulse stimulus type increased with age. Degrees of freedom: 2; error degrees of freedom: 192 
A

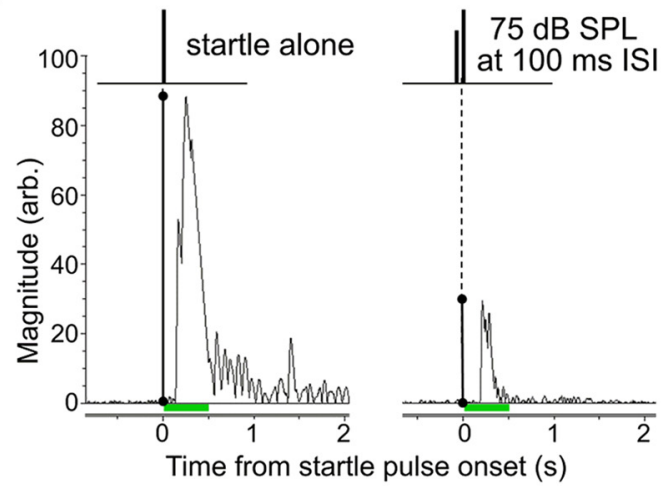

C

\section{$75 \mathrm{~dB}$ SPL, 30ms}

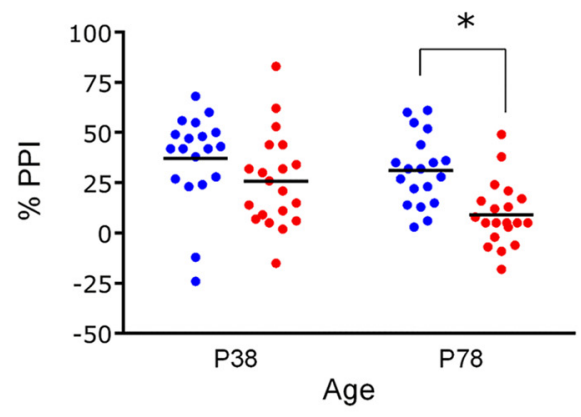

$85 \mathrm{~dB}$ SPL, 30ms

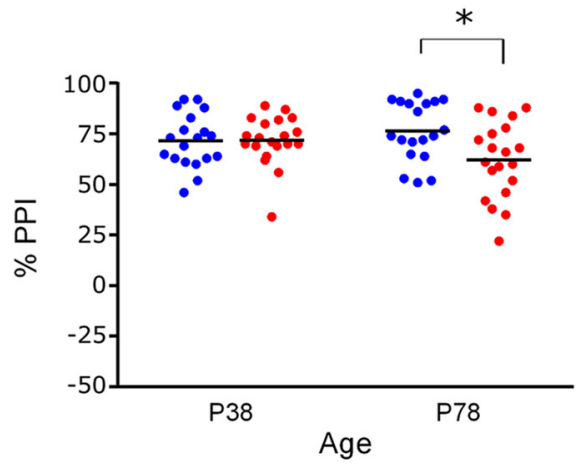

B Baseline Startle

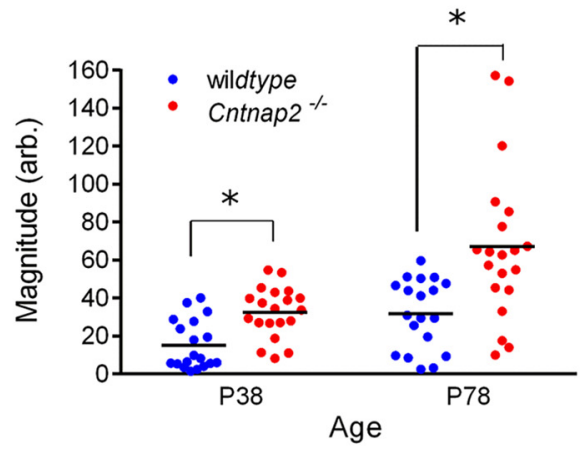

$75 \mathrm{~dB}$ SPL, 100ms

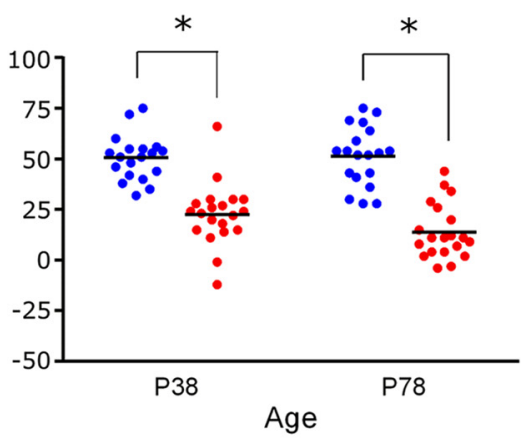

$85 \mathrm{~dB}$ SPL, 100ms

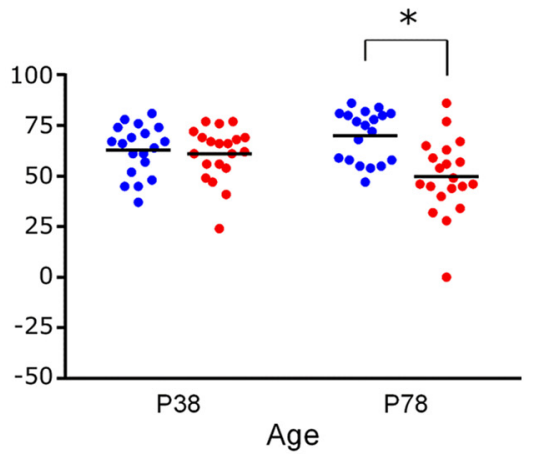

Figure 7. Sensorimotor gating measured as percentage PPI revealed a gating deficit that worsens with age. A, Representative raw ASR traces from an adult male wild-type rat depicts the ASR magnitude (black bars) to a startle pulse (105 dB SPL) alone or preceded by a prepulse stimulus ( $75 \mathrm{~dB} \mathrm{SPL,} 100 \mathrm{~ms}$ ISI) as measured by the STARTLE software module. Green bars indicate the 500 ms ASR recording window. B, Because startle reactivity can affect sensorimotor gating (Csomor et al., 2008), differences in baseline startle magnitude were calculated using the startle-only trials during PPI blocks and analyzed (age $\times$ genotype $\times$ sex). A three-way interaction was found $\left(F_{(2,64)}=3.32, p=0.043\right)$. Because sex did not interact with genotype $\left(F_{(2,64)}=2.76, p=0.071\right)$, age $\left(F_{(2,64)}=3.88, p=0.053\right)$, or have a main effect $\left(F_{(2,64)}=3.84, p=0.054\right)$, the simple main effect of genotype and post hoc $t$ tests were analyzed at P38 and P78. (ntnap2 ${ }^{-/-}$rats (red) had a significantly greater startle response magnitude to the $105 \mathrm{~dB}$ startle stimulus compared with wild-type rats (blue) despite being the same weight or less (P38, $p=0.026 ; \mathrm{P} 78, p<0.0001 ;$ see above). Scatter plots depict individual data, with the horizontal line representing the mean ASR magnitude. (ntnap2 ${ }^{+/-}$rats did not differ from wild-types at P38 or P72 (data not shown). C, Scatter plots depicting individual data for each prepulse condition, with the horizontal line representing the mean percentage PPI in wild-type (blue) and (ntnap2 ${ }^{-1-}$ (red) animals at P38 and P78. Cntnap2 ${ }^{-1-}$ rats exhibit reduced PPI in the $75 \mathrm{~dB}$ SLP, $100 \mathrm{~ms}$ ISI prepulse condition when young, which extends to all conditions upon adulthood, indicative of a sensorimotor gating deficit that worsens with aging. Asterisks indicate $p<0.05$.

(DCN; -11.04 to -11.28 bregma), the caudal pontine reticular nucleus (PnC; -10.08 to -10.20 bregma), the superior olivary complex ( -10.08 to -10.20 bregma), the cochlear nerve ( $8 \mathrm{n}$; -10.08 to -10.20 bregma), the ventral cochlear nucleus $(-10.08$ to -10.20 bregma), the pedunculopontine tegmental nucleus (PPT; -8.16 to -8.28 bregma), and the dorsal nucleus of the lateral lemniscus ( -8.16 to -8.28 bregma).

\section{Discussion}

To our knowledge, the present study represents the first systematic longitudinal investigation of brainstem auditory processing and auditory reactivity disruptions in an animal model for ASD with very high construct and face validity. It is also the first report on sensory processing and reactivity of the novel Cntnap 2 knockout rat model. Neural measures of hearing sensitivity, responsiv- 
Table 4. Statistical table for the simple main effect of genotype on the change in latency to maximum startle response for a prepulse stimulus type and age

\begin{tabular}{llccc}
\hline Prepulse type & Age & F-statistic & $p$-value & Effect size \\
\hline $75 \mathrm{~dB} \mathrm{SPL}$ & 38 & 12.5 & $<0.0001$ & 0.12 \\
$30 \mathrm{~ms}$ & 78 & 0.58 & 0.560 & - \\
$75 \mathrm{~dB} \mathrm{SPL}$ & 38 & 3.01 & 0.051 & - \\
$100 \mathrm{~ms}$ & 78 & 8.44 & 0.0003 & 0.08 \\
$85 \mathrm{~dB} \mathrm{SPL}$ & 38 & 53.1 & $<0.0001$ & 0.36 \\
$30 \mathrm{~ms}$ & 78 & 19.8 & $<0.0001$ & 0.17 \\
$85 \mathrm{~dB}$ SPL & 38 & 39.9 & $<0.0001$ & 0.29 \\
$100 \mathrm{~ms}$ & 78 & 39.5 & $<0.0001$ & 0.29
\end{tabular}

Degrees of freedom: 2; error degrees of freedom: 192. ity, and speed of transmission, as well as behavioral measures of acoustic reactivity, filtering, and sensorimotor gating were assessed to allow a broad understanding of auditory brainstem dysfunction and the behavioral consequences thereof. We found that the homozygous knock-out rats have typical hearing sensitivity (threshold), but reduced auditory evoked neural responsivity and slowed signal transmission throughout different levels of the brainstem in adolescence. Behaviorally, animals showed increased reactivity to acoustic stimuli and disruptions in habituation and PPI. Interestingly, the disruptions in auditory signal processing mostly disappeared by adulthood, indicating that they are caused by a delay in maturation of the auditory pathway,

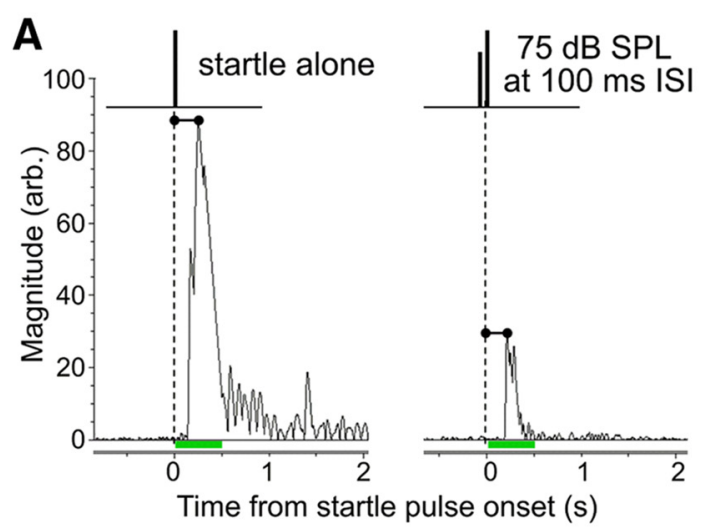

C $\quad 75 \mathrm{~dB} \mathrm{SPL}, 30 \mathrm{~ms}$

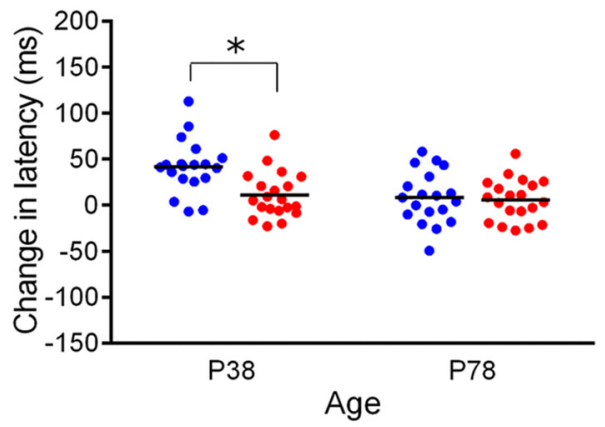

$85 \mathrm{~dB} \mathrm{SPL}, 30 \mathrm{~ms}$

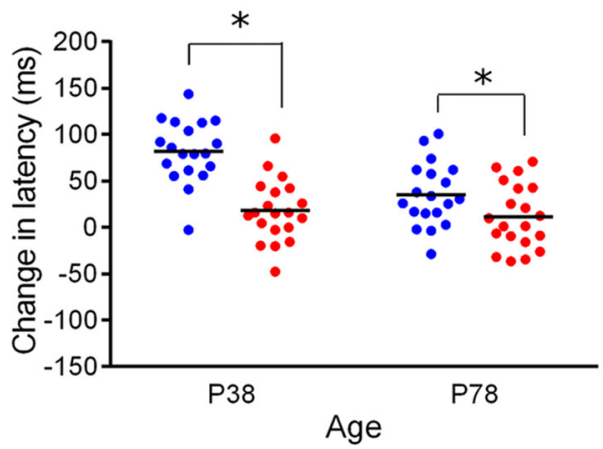

B Baseline Startle

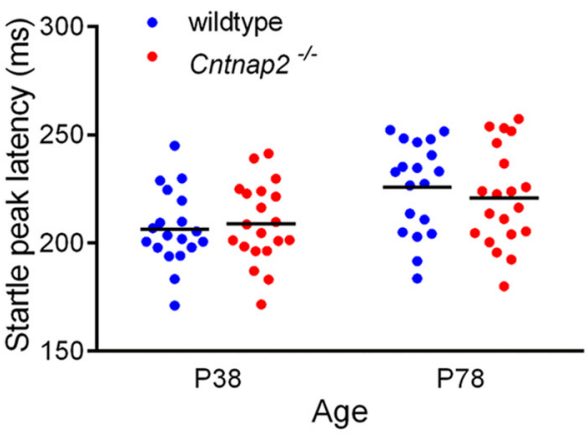

$75 \mathrm{~dB}$ SPL, $100 \mathrm{~ms}$
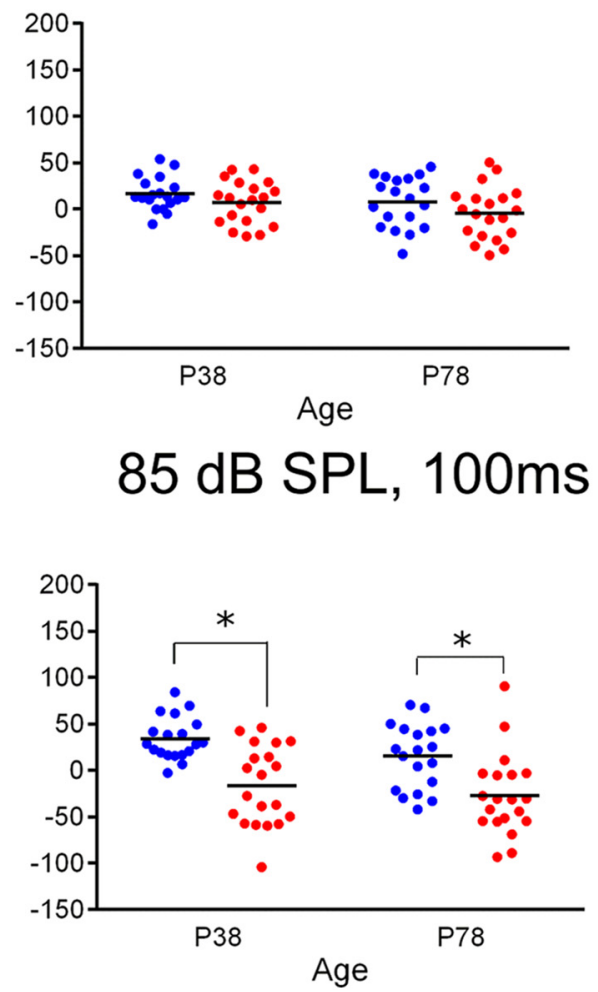

Figure 8. Sensorimotor gating measured by the latency to ASR. $A$, Representative raw ASR traces from an adult male wild-type rat as measured by the STARTLE software module depicting the latency to ASR (black bars) elicited by a startle pulse of $105 \mathrm{~dB}$ SPL presented alone or preceded by a prepulse stimulus (75 dB SPL, $100 \mathrm{~ms} I S \mathrm{SI})$. Green bars indicate the $500 \mathrm{~ms}$ ASR recording window. $B$, No differences in the latency to baseline ASR peak were found because there was no main effect of genotype $\left(F_{(2,64)}=0.28, p=0.755\right)$ nor any interactions involving genotype. Therefore, any latency effects observed when a prepulse was presented are not confounded by baseline startle differences. Scatter plots depict individual data, with the horizontal line representing the mean ASR latency. $\boldsymbol{C}$, Values $>1$ indicate an increased latency to the ASR compared with the startle pulse only condition. Scatter plots depict individual data for each prepulse condition, with the horizontal line

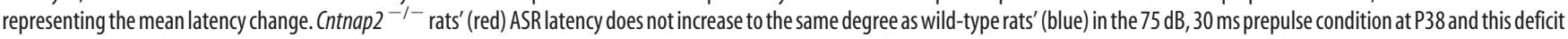
can be seen in the $85 \mathrm{~dB}$ conditions in young and adult animals. Asterisks indicate $p<0.05$. 
A

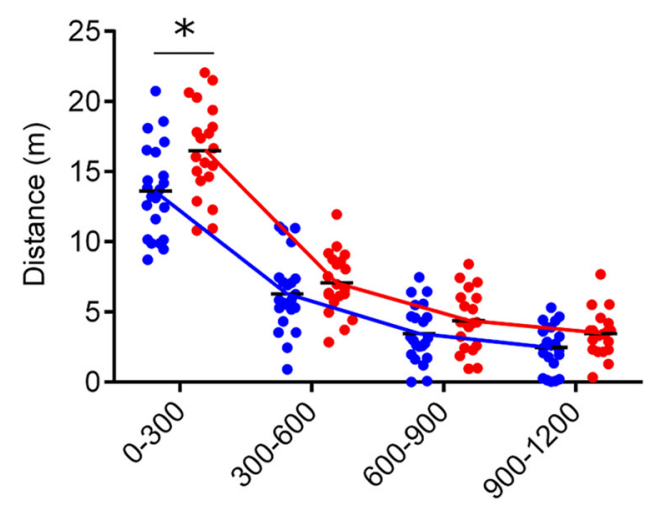

Time (s)

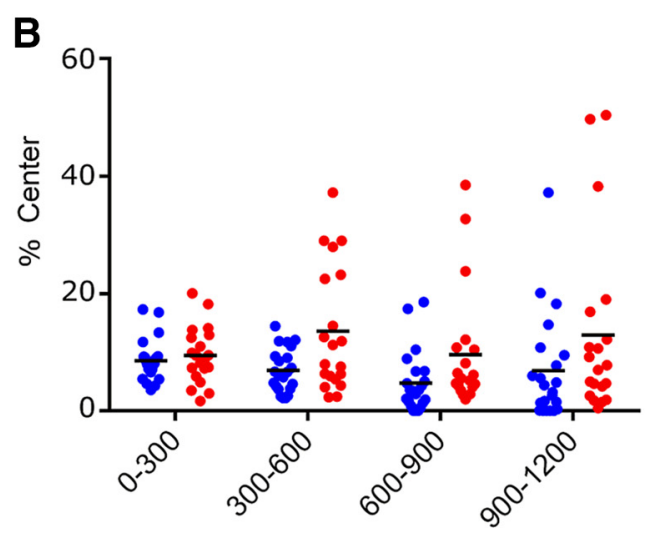

Time (s)
P78

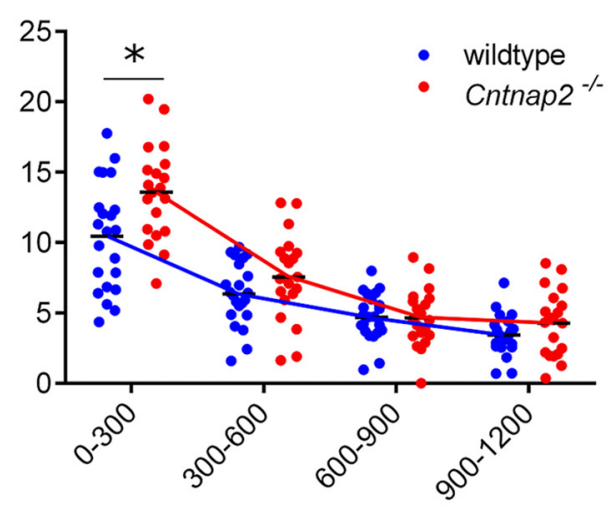

Time (s)

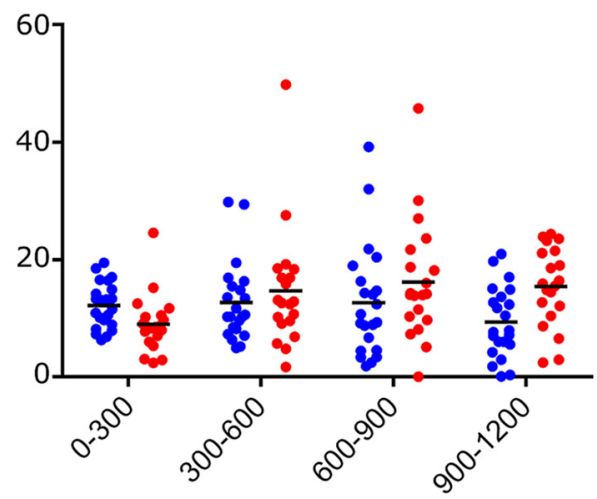

Time (s)

Figure 9. Locomotor measures of hyperactivity and anxiety. $A$, Exploratory behavior was measured using 5 min bins for a total time of 20 min in wild-type (blue) and Cntnap ${ }^{-1-}$ (red) rats at P38 and P78. Scatter plot depicts individual data with horizontal line representing the mean distance traveled. At both P38 and P78, Cntnap2 ${ }^{-1-}$ rats travel a greater distance in the first 5 min epoch compared with wild-type rats, indicative of a hyperactive phenotype that does habituate over time. $\boldsymbol{B}$, Percentage time spent in center was used as a measure of an anxiety-like phenotype. Scatter plot depicts individual data with horizontal line representing the mean distance traveled. Asterisks indicate $p<0.05$.

Table 5. Statistical table for the simple main effect of genotype on the percentage of time spent in the center of a locomotor box for a given time bin and age

\begin{tabular}{llllc}
\hline Time bin & Age & F-statistic & $p$-value & Effect size \\
\hline $0-300 \mathrm{~ms}$ & 38 & 0.22 & 0.80 & - \\
& 78 & 1.36 & 0.26 & - \\
$300-600 \mathrm{~ms}$ & 38 & 7.0 & 0.001 & 0.064 \\
& 78 & 0.49 & 0.61 & - \\
$600-900 \mathrm{~ms}$ & 38 & 3.11 & 0.047 & 0.03 \\
& 78 & 1.31 & 0.27 & - \\
$900-1200 \mathrm{~ms}$ & 38 & 6.23 & 0.002 & 0.058 \\
& 78 & 6.89 & 0.001 & 0.063 \\
\hline
\end{tabular}

Degrees of freedom: 2; error degrees of freedom: 204.

whereas increased behavioral reactivity and disruptions in sensorimotor gating persisted in adulthood. The minor differences in heterozygous knock-out animals compared with wild-types are also important because humans with disruptions in the CNTNAP2 gene other than a complete loss-offunction present with minor language problems and milder forms of neurodevelopmental disorder (Whalley et al., 2011; Whitehouse et al., 2011; Poot, 2015).

\section{Brainstem responsivity and reactivity}

ABR wave amplitudes were assessed to determine whether the peripheral brainstem (I: cochlear nerve) versus central brain- stem (IV: lateral lemniscus terminating at the inferior colliculus) responsivity was affected in Cntnap2 knock-out animals. In cases of peripheral deficits such as cochlear synaptopathy, loss of auditory nerve fibers, or noise-induced hidden hearing loss, reduced wave I amplitudes have been reported (Sergeyenko et al., 2013; Bourien et al., 2014; Shi et al., 2016). Because we observed no differences in the amplitude of wave I between Cntnap $2^{-1-}$ and wild-type animals, we suggest that peripheral auditory function is preserved in these animals (Fig. 3). This is further supported by the lack of ABR threshold differences (Fig. 2). However, acoustic startle reactivity, which is a behavioral read-out of brainstem auditory signaling (Fig. 10), is increased in knock-out animals and this worsens with age, as indicated by the leftward shift of the startle reactivity curve (Fig. 5B). Therefore, the underlying mechanism for the overreactivity in Cntnap2 knock-out animals must occur outside of the primary auditory pathway, possibly in the sensorimotor interface of the startle pathway, the PnC, where cochlear root neurons synapse on premotor neurons (for review, see Koch, 1999; Larrauri and Schmajuk, 2006; Simons-Weidenmaier et al., 2006; Fig. 10, green). Importantly, both the electrophysiological and behavioral phenotypic pattern reported here parallel those reported in individuals with ASD (for review, see Sinclair et al., 2017). 

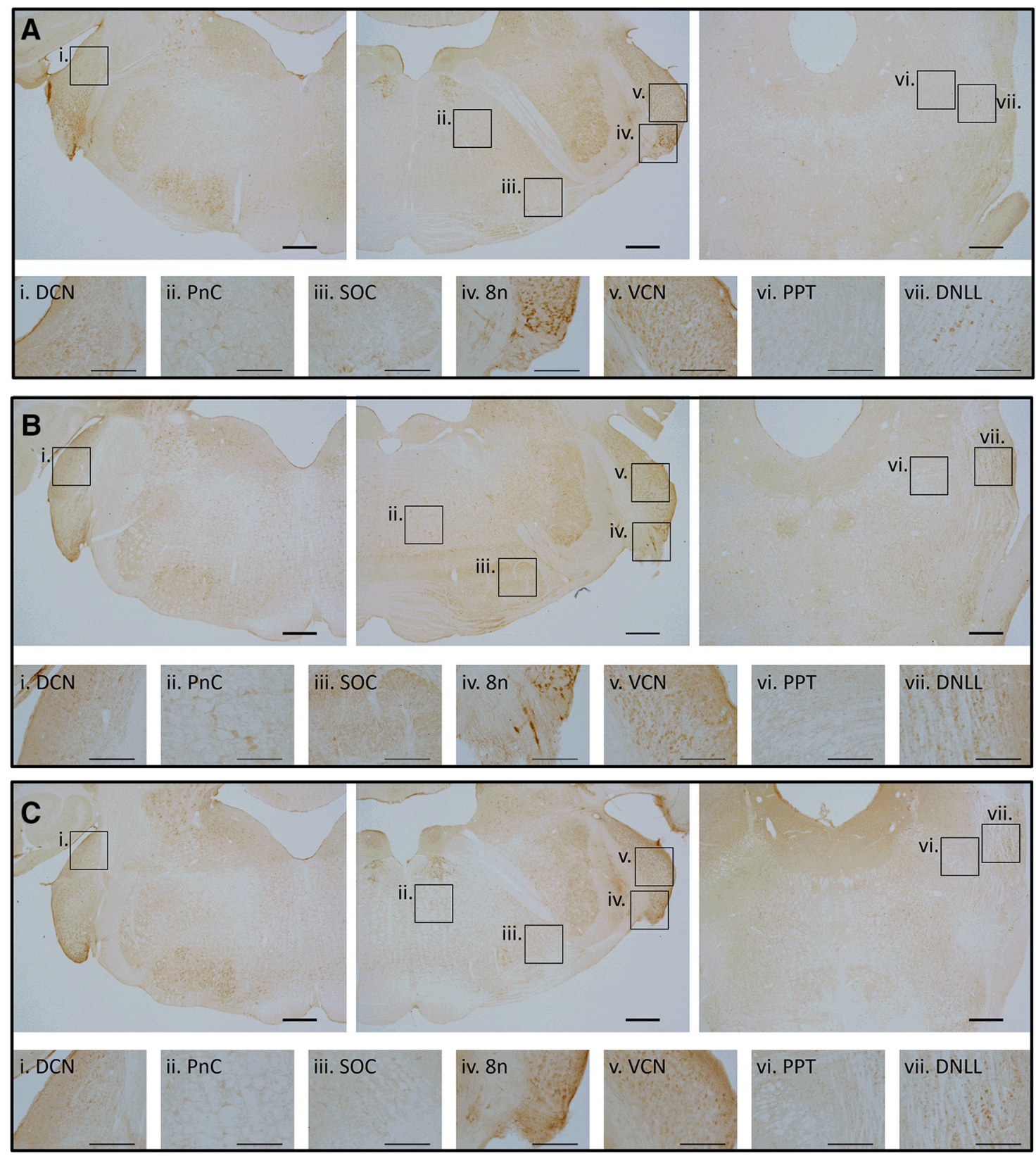

Figure 10. CASPR2 expression across development. Representative images of CASPR2 expression in wild-type rats at P28 (A), P42 (B), and P70 ( () in the dorsal cochlear nucleus (DCN; i), caudal pontine reticular nucleus (PnC; ii), superior olivary complex (SOC; iii), cochlear nerve (8n; iv), ventral cochlear nucleus (VCN; v), PPT (vi), and the dorsal nucleus of the lateral lemniscus (DNLL; vii). Scale bars are $500 \mu \mathrm{m}$ in the large images and $200 \mu \mathrm{m}$ in the small images.

Interestingly, whereas ASR magnitudes increase during development, habituation of this response improves with age. Startle habituation is a normalized measure and therefore can be quantified independently from changes in baseline startle. Baseline startle responses rely on the glutamatergic excitation of PnC giant neurons, whereas habituation relies on synaptic depression at the axon terminals of the sensory afferents in the PnC, likely mediated by voltage- and calcium-activated potassium channel function (Ebert and Koch, 1992; Weber et al., 2002; SimonsWeidenmaier et al., 2006; Zaman et al., 2017; Fig. 11). Given the presence of CASPR2 in cochlear root neurons as well as the giant neurons of the PnC (Fig. 10) and its association with potassium channels (Kv1.2) at the soma membrane or axon initial segment (Inda et al., 2006; Dawes et al., 2018), one can speculate that CASPR2 affects startle through influencing PnC excitability and that it interferes directly with startle habituation through its function in clustering potassium channels.

An analysis of the activity thought to arise from the superior olivary complex (ABR peak III) shows a clear effect of genotype across age, with differences persisting but decreasing with development. The ABR wave representing the lateral lemniscus/inferior colliculus in humans is more variable and therefore is not often studied because of its lack of clinical applicability (Rosenhall et al., 2003). However, alterations in peak amplitude hold important information about the number, individual contribution, and synchronization of neuronal components because alterations in any of these factors can lead to differences in wave amplitudes. It remains to be determined which of these aspects is disrupted in Cntnap 2 knock-out rats. Differences in the wave IV:I ratio can provide an indication of gain changes in the brainstem; 


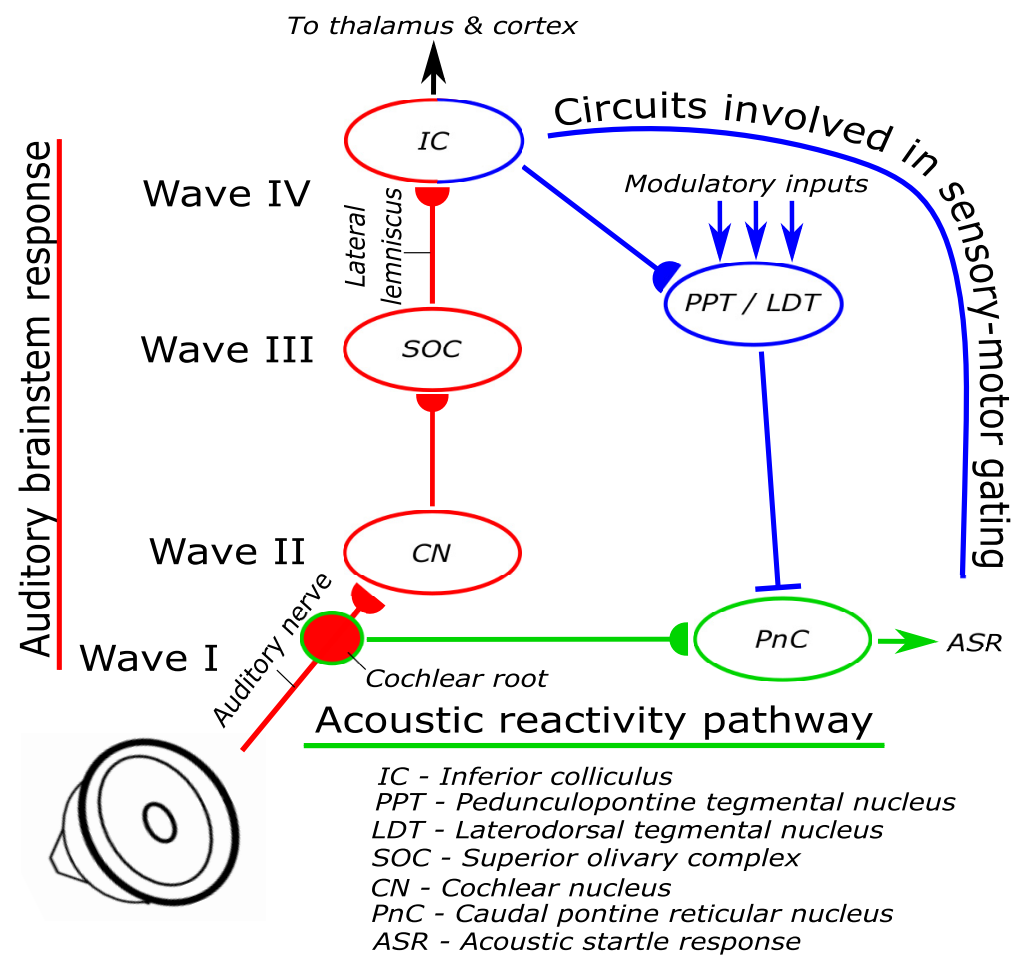

Figure 11. Generalized circuit outlining relevant auditory brainstem structures. The measures of hearing sensitivity, neural responsivity, and speed of neurotransmission were obtained from the ABR. Acoustic reactivity and sensory filtering (i.e., habituation) rely on the acoustic reactivity pathway and sensorimotor gating is dependent on the interplay of both circuits (Koch, 1999; Larrauri and Schmajuk, 2006; Yeomans et al., 2006).

Table 6. Auditory brainstem response descriptive table for the wave IV:I ratio analysis

\begin{tabular}{lllll}
\hline Genotype & Rats with ratio $<1(\%)$ & Range & Mean & SEM \\
\hline Cntnap2 $^{-1-}$ & 47.1 & $0.65-1.77$ & 1.12 & \pm 0.08 \\
Wild-type $^{-1.12}$ & 0.0 & $1.30-2.18$ & 1.70 & \pm 0.05 \\
\hline
\end{tabular}

therefore, the smaller ratio reported in young Cntnap $2^{-1-}$ rats indicates that the central brainstem specifically is less responsive during development, but eventually normalizes with age (Fig. 3). A single study in the ASD population has looked at a similar phenomenon and reported that children (age 2-6 years) with ASD and language delay exhibited higher amplitudes of wave 1 than wave V (35\%) more frequently than the control group (Santos et al., 2017). Amazingly, the Cntnap $2^{-1-}$ rats show the same pattern at P28, such that $47 \%$ have a larger wave I than wave IV amplitude (resulting in a wave IV:I ratio <1.0) compared with $0 \%$ of wild-type (Table 6 ).

Importantly, sensorimotor gating relies on these central components of the auditory brainstem. For example, lesioning the inferior colliculus causes both a greater startle response and prevents inhibition of startle by a prepulse (Leitner and Cohen, 1985). PPI is impaired in knock-out rats (Figs. 7, 10), so the reduced PPI might directly reflect the reduced responsivity of wave IV, which may be caused by signal strength loss if synapses are not properly developed (Poot, 2015; Murphy and BenítezBurraco, 2016). This is more evident in the $75 \mathrm{~dB}$ prepulse condition at both ages because, at greater prepulse intensities (i.e., 85 $\mathrm{dB}$ ), there might be a saturation of startle inhibition (ceiling effect). Interestingly, the wave IV amplitudes improve with age whereas PPI deficits persist. This persistent PPI deficit may be caused by the increased baseline startle in knock-out animals because the amount of PPI is influenced by baseline startle am- plitudes such that higher baseline startle is accompanied by poorer inhibition by prepulses (Csomor et al., 2008). However, significant correlations were, for the most part, not observed between PPI and baseline startle in wild-type or knock-out animals in any prepulse condition (exception: Cntnap $2^{-1-}$, P78, $75 \mathrm{~dB}$ SPL 100 ISI condition: $R^{2}=0.203, p=0.046$ ). It remains to be determined to what extent PPI deficits are caused by aberrant signal processing in the higher brainstem due to the disruptions during development as a result of the loss of Cntnap2, by the higher baseline startle, or by additional topdown modulatory effects from cortical areas. In any case, this same pattern has been described in humans with autism, in whom increased startle reactivity is accompanied by a PPI deficit (Perry et al., 2007). Furthermore, the top-down modulation by higher auditory areas via the PPT have been shown to affect both the baseline magnitude of the ASR as well as its inhibition by prepulse stimuli (Fendt et al., 2001; Larrauri and Schmajuk, 2006; Fig. 10, blue). Therefore, the Cntnap $2^{-1-}$ rats' PPI deficit is likely a result of aberrant neural brainstem responsivity to stimulus intensity and increased acoustic startle reactivity.

\section{Speed of neurotransmission and startle response latency}

The speed of neural transmission in the inner ear and auditory nerve has implications for latency to maximum startle response. Knock-out animals show typical startle latencies, suggesting that the synapse from the inner hair cells to the auditory nerve, synapses in the cochlear root, axonal conduction, as well as synaptic transmission along the motor part of the startle pathway are not affected in terms of speed (Fig. 10, green). This is consistent with our finding that the wave I latency was also normal in Cntnap2 knock-out animals. In humans with autism, prolonged startle response latencies have been reported; however, startle measures in humans normally measure an electromyogram of the eyeblink reflex, which is one component of the overall startle and might be dependent on a slightly different neural circuit (Yuhas et al., 2011; Takahashi et al., 2014, 2016). In contrast to these early auditory processing stages that were not affected in knock-out animals, we found an increased latency between the auditory nerve (wave I) and cochlear nucleus (wave II) that seemed to at least partly persist into adulthood, suggesting deficits in either axonal conduction time and/or the synapse onto the cochlear nucleus (i.e., endbulb of Held; Rosenhall et al., 2003). Studies of Cntnap2 knock-down mice showed no differences in the conduction velocity or refractory periods of the optic or sciatic nerves. Importantly, there is a close correspondence between synapse function and $A B R$ maturation and the endbulb of Held synapse has been shown to be crucial for temporal precision (Blatchley et al., 1987; Poliak et al., 2003; Yu and Goodrich, 2014). This is particularly relevant given Cntnap2's function in synapse development and maintenance and thus synaptic transmission in developing neurons (Poot, 2015; Murphy and Benítez-Burraco, 2016). Importantly, Kv1 channels with which CASPR2 is associ- 
ated contribute to the precise temporal pattern of synaptic transmission are present in high concentrations in the soma of cells within the cochlear nucleus and exhibit an age-related increase in mRNA level expression before leveling off at P56 (Bortone et al., 2006; Robbins and Tempel, 2012). Therefore, altered synaptic function is the more likely cause for the increased IPL I-II, as well as for the delay in subsequent ABR waves. The Cntnap $2^{-1-}$ rat is first rodent model to recapitulate the slowed brainstem neurotransmission reported in ASD (Wong and Wong, 1991; Rosenhall et al., 2003; Kwon et al., 2007; Tas et al., 2007; Fujikawa-Brooks et al., 2010; Magliaro et al., 2010; Gonçalves et al., 2011; Roth et al., 2012; Miron et al., 2016). The slower IPL I-II partially and both the prolonged IPL II-IV and absolute latencies of wave II, III, and IV of Cntnap $2^{-/-}$animals fully normalize by adulthood (Fig. 4, Table 1), suggesting that this reflects a delay in brainstem development, which, again, has been reported to be associated with ASD (Fuess et al., 2002; Amorim et al., 2009). Studies have also found a delayed maturation of cortical auditory processing in autism (Gage et al., 2003; Edgar et al., 2015). Given that cortical development relies on the brainstem, it is highly likely this phenotype is also present in Cntnap $2^{-1-}$ animals and is an exciting consideration for future studies.

Studies in rats exploring the neural substrates of sensorimotor gating have noted that prepulse effects on startle latency occur separately from PPI (i.e., startle amplitude), so PPI deficits cannot simply reflect reduced prepulse detection because latency modulation may still remain intact (Ison et al., 1973; Swerdlow et al., 1992). Two previous studies support this conclusion because the presence of PPI deficits in animal models of schizophrenia was not associated with differences in startle latency (Lyall et al., 2009; Marriott et al., 2016). This is further exemplified in the present study, in which Cntnap $2^{-1-}$ rats exhibited greater baseline startle responses without effects on latency (Figs. 8, 9A). Startle latency typically increases in PPI trials with ISIs $>30 \mathrm{~ms}$ (Ison et al., 1973; Hoffman and Ison, 1980; Fig. 8B). Although mostly confirmed in our wild-type controls, Cntnap $2^{-1-}$ animals did not only show deficient PPI (amplitudes), but also a lack of increased latencies in PPI trials; in fact, latency sometimes decreased. Because latency and amplitude manipulations by prepulse stimuli are thought to be independent phenomena (Hoffman and Ison, 1980; Hutchison et al., 2000), these results suggest robust deficits in sensorimotor gating in the knock-out animals.

\section{Comparison with other animal models of autism}

Our collective results are consistent with much of what is observed in individuals with autism; however, they do differ from findings in the Cntnap2 knock-out mice. Behaviorally, no startle differences were reported in Cntnap2 knock-out mice and PPI differences vary with experimental protocol (Peñagarikano et al., 2011; Brunner et al., 2015; Truong et al., 2015). Our results also differ from studies on Fmrl knock-out mice and rats, a model for fragile $\mathrm{X}$ syndrome. With respect to the $\mathrm{ABR}$, fragile $\mathrm{X}$ mice show smaller wave I and III peak amplitudes and no latency differences (Rotschafer et al., 2015). Behaviorally, Fmrl knock-out rats show typical startle responses and no significant PPI differences. However, results in the mouse literature vary, with some showing increased startle responses to low intensity sounds as found in our Cntnap2 knock-out rats, but reduced startle to high intensity sound (Nielsen et al., 2002; Hamilton et al., 2014; Sinclair et al., 2017). Adult mice with a FOXP2 missense mutation exhibit a more similar pattern to the juvenile Cntnap 2 knock-out rats, with prolonged ABR latencies and reduced wave I and IV amplitudes (Kurt et al., 2009). This is promising because FOXP2 transcrip- tion factor regulates CNTNAP2 gene expression (Vernes et al., 2008; Rodenas-Cuadrado et al., 2014; Poot, 2015), revealing a common path for auditory dysfunction. Last, the greater locomotor activity observed in this study is consistent with previous studies in the Cntnap2 knock-out rats, as is the observed presence of motor seizures in the adult rats (Thomas et al., 2016). Interestingly, other rodent models with knocked out Kv1.1 or Kv1.2 also have a seizure pathology, highlighting the potential importance of examining potassium channel function as a mechanism for altered excitability in ASD (Robbins and Tempel, 2012).

Overall, our findings show that alterations in sensory processing during early development due to the delayed maturation of the auditory pathway are associated with alterations in behavioral reactivity that persist in adulthood, emphasizing the need for early interventions targeting sensory processing to prevent potential maladaptive behavioral changes. Our results also validate a new rat model for studying auditory system dysfunction with high relevance to ASD (Poot, 2015, 2017; Servadio et al., 2015). Future studies need to explore cellular and molecular mechanisms that can be targeted to rectify altered auditory processing and behavioral reactivity.

\section{References}

Abitbol JM, Kelly JJ, Barr K, Schormans AL, Laird DW, Allman BL (2016) Differential effects of pannexins on noise-induced hearing loss. Biochem J 473:4665-4680. CrossRef Medline

Abrahams BS, Tentler D, Perederiy JV, Oldham MC, Coppola G, Geschwind DH (2007) Genome-wide analyses of human perisylvian cerebral cortical patterning. Proc Natl Acad Sci U S A 104:17849-17854. CrossRef Medline

Alarcón M, Abrahams BS, Stone JL, Duvall JA, Perederiy JV, Bomar JM, Sebat J, Wigler M, Martin CL, Ledbetter DH, Nelson SF, Cantor RM, Geschwind DH (2008) Linkage, association, and gene-expression analyses identify CNTNAP2 as an autism-susceptibility gene. Am J Hum Genet 82:150-159. CrossRef Medline

Altman N, Krzywinski M (2015) Points of significance: split plot design. Nat Methods 12:165-166. CrossRef Medline

Alvarado JC, Fuentes-Santamaría V, Jareño-Flores T, Blanco JL, Juiz JM (2012) Normal variations in the morphology of auditory brainstem response (ABR) waveforms: a study in wistar rats. Neurosci Res 73:302-311. CrossRef Medline

Amorim RB, Agostinho-Pesse RS, Alvarenga Kde F (2009) The maturational process of the auditory system in the first year of life characterized by brainstem auditory evoked potentials. J Appl Oral Sci 17:57-62. CrossRef Medline

Arking DE, Cutler DJ, Brune CW, Teslovich TM, West K, Ikeda M, Rea A, Guy M, Lin S, Cook EH Jr, Chakravati A (2008) A common genetic variant in the neurecin superfamily member CNTNAP2 increases familial risk of autism. Am J Hum Genet 82:160-164. CrossRef Medline

Blatchley BJ, Cooper WA, Coleman JR (1987) Development of auditory brainstem response to tone pip stimuli in the rat. Brain Res 429:75-84. CrossRef Medline

Bortone DS, Mitchell K, Manis PB (2006) Developmental time course of potassium channel expression in the rat cochlear nucleus. Hear Res 211: 114-125. CrossRef Medline

Bourien J, Tang Y, Batrel C, Huet A, Lenoir M, Ladrech S, Desmadryl G, Nouvian R, Puel JL, Wang J (2014) Contribution of auditory nerve fibres to compound action potential of the auditory nerve. J Neurophysiol 112:1025-1039. CrossRef Medline

Brunner D, Kabitzke P, He D, Cox K, Thiede L, Hanania T, Sabath E, Alexandrov V, Saxe M, Peles E, Mills A, Spooren W, Ghosh A, Feliciano P, Benedetti M, Luo Clayton A, Biemans B (2015) Comprehensive analysis of the $16 \mathrm{p} 11.2$ deletion and null cntnap2 mouse models of autism spectrum disorder. PLoS One 10:e0134572. CrossRef Medline

Chamberlain PD, Rodgers J, Crowley MJ, White SE, Freeston MH, South M (2013) A potentiated startle study of uncertainty and contextual anxiety in adolescents diagnosed with autism spectrum disorder. Mol Autism 4:31. CrossRef Medline

Church MW, Kaltenbach JA (1993) The hamster's auditory brain stem re- 
sponse as a function of stimulus intensity, tone burst frequency, and hearing loss. Ear Hear 14:249-257. CrossRef Medline

Csomor PA, Yee BK, Vollenweider FX, Feldon J, Nicolet T, Quednow BB (2008) On the influence of baseline startle reactivity on the indexation of prepulse inhibition. Behav Neurosci 122:885-900. CrossRef Medline

Danesh AA, Lang D, Kaf W, Andreassen WD, Scott J, Eshraghi AA (2015) Tinnitus and hyperacusis in autism spectrum disorders with emphasis on high functioning individuals diagnosed with Asperger's Syndrome. Int J Pediatr Otorhinolaryngol 79:1683-1688. CrossRef Medline

Dawes JM, et al. (2018) Immune or genetic-mediated disruption of CASPR2 causes pain hypersensitivity due to enhanced primary afferent excitability. Neuron 97:806-822.e10. CrossRef Medline

Deriziotis P, Fisher SE (2017) Speech and language: translating the genome. Trends Genet 33:642-656. CrossRef Medline

Ebert U, Koch M (1992) Glutamate receptors mediate acoustic input to the reticular brain stem. Neuroreport 3:429-432. CrossRef Medline

Edgar JC, Fisk Iv CL, Berman JI, Chudnovskaya D, Liu S, Pandey J, Herrington JD, Port RG, Schultz RT, Roberts TP (2015) Auditory encoding abnormalities in children with autism spectrum disorder suggest delayed development of auditory cortex. Mol Autism 6:69. CrossRef Medline

Fendt M, Li L, Yeomans JS (2001) Brain stem circuits mediating prepulse inhibition of the startle reflex. Psychopharmacology (Berl) 156:216-224. CrossRef Medline

Santos M, Marques C, Nóbrega Pinto A, Fernandes R, Coutinho MB, Almeida E Sousa C (2017) Autism spectrum disorders and the amplitude of auditory brainstem response wave I. Autism Res 10:1300-1305. CrossRef Medline

Fuess VL, Bento RF, da Silveira JA (2002) Delay in maturation of the audiotry pathway and its relationship to language acquisition disorders. Ear Nose Throat J 81:706-710, 712. Medline

Fujikawa-Brooks S, Isenberg AL, Osann K, Spence MA, Gage NM (2010) The effect of rate stress on the auditory brainstem response in autism: a preliminary report. Int J Audiol 49:129-140. CrossRef Medline

Gage NM, Siegel B, Roberts TP (2003) Cortical auditory system maturational abnormalities in children with autism disorder: an MEG investigation. Brain Res Dev Brain Res 144:201-209. CrossRef Medline

Gonçalves IC, Wertzner HF, Samelli AG, Matas CG (2011) Speech and nonspeech processing in children with phonological disorders: an electrophysiological study. Clinics (Sao Paulo) 66:293-298. CrossRef Medline

Gordon A, Salomon D, Barak N, Pen Y, Tsoory M, Kimchi T, Peles E (2016) Expression of Cntnap2 (Caspr2) in multiple levels of sensory systems. Mol Cell Neurosci 70:42-53. CrossRef Medline

Graham FK (1975) The more or less startling effects of weak prestimulation. Psychophysiology 12:238-248. CrossRef Medline

Graham FK, Murray GM (1977) Discordant effects of weak prestimulation on magnitude and latency of the reflex blink. Physiological Psychology 5:108-114. CrossRef

Hamilton SM, Green JR, Veeraragavan S, Yuva L, McCoy A, Wu Y, Warren J, Little L, Ji D, Cui X, Weinstein E, Paylor R (2014) Fmr1 and Nlgn3 knockout rats: novel tools for investigating autism spectrum disorders. Behav Neurosci 128:103-109. CrossRef Medline

Hitoglou M, Ververi A, Antoniadis A, Zafeiriou DI (2010) Childhood autism and auditory system abnormalities. Pediatr Neurol 42:309-314. CrossRef Medline

Hoffman HS, Ison JR (1980) Reflex modification in the domain of startle: I. some empirical findings and their implications for how the nervous system processes sensory input. Psychol Rev 87:175-189. CrossRef Medline

Hoffman HS, Wible BL (1970) Role of weak signals in acoustic startle. J Acoust Soc Am 47:489-497. Medline

Hutchison KE, Niaura R, Swift R (2000) The effects of smoking high nicotine cigarettes on prepulse inhibition, startle latency, and subjective responses. Psychopharmacology (Berl) 150:244-252. CrossRef Medline

Inda MC, DeFelipe J, Muñoz A (2006) Voltage-gated ion channels in the axon initial segment of human cortical pyramidal cells and their relationship with chandelier cells. Proc Natl Acad Sci U S A 103:2920-2925. CrossRef Medline

Ison JR, McAdam DW, Hammond GR (1973) Latency and amplitude changes in the acoustic startle reflex of the rat produced by variation in auditory prestimulation. Physiol Behav 10:1035-1039. CrossRef Medline

Khalfa S, Bruneau N, Rogé B, Georgieff N, Veuillet E, Adrien JL, Barthélémy C, Collet L (2004) Increased perception of loudness in autism. Hear Res 198:87-92. CrossRef Medline
Kjelgaard MM, Tager-Flusberg H (2001) An investigation of language impairment in autism: implications for genetic subgroups. Lang Cogn Process 16:287-308. CrossRef Medline

Koch M (1999) The neurobiology of startle. Prog Neurobiol 59:107-128. CrossRef Medline

Kohl S, Wolters C, Gruendler TO, Vogeley K, Klosterkötter J, Kuhn J (2014) Prepulse inhibition of the acoustic startle reflex in high functioning autism. PLoS One 9:e92372. CrossRef Medline

Kurt S, Groszer M, Fisher SE, Ehret G (2009) Modified sound-evoked brainstem potentials in Foxp2 mutant mice. Brain Res 1289:30-36. CrossRef Medline

Kwon S, Kim J, Choe BH, Ko C, Park S (2007) Electrophysiologic assessment of central auditory processing by auditory brainstem responses in children with autism spectrum disorders. J Korean Med Sci 22:656-659. CrossRef Medline

Larrauri J, Schmajuk N (2006) Prepulse inhibition mechanisms and cognitive processes: a review and model. EXS 98:245-278. Medline

Leitner DS, Cohen ME (1985) Role of the inferior colliculus in the inhibition of acoustic startle in the rat. Physiol Behav 34:65-70. CrossRef Medline

Lyall A, Swanson J, Liu C, Blumenthal TD, Turner CP (2009) Neonatal exposure to MK801 promotes prepulse-induced delay in startle response time in adult rats. Exp Brain Res 197:215-222. CrossRef Medline

Magliaro FC, Scheuer CI, Assumpção Júnior FB, Matas CG (2010) Study of auditory evoked potentials in autism. Pro Fono 22:31-36. CrossRef Medline

Marriott AL, Tasker RA, Ryan CL, Doucette TA (2016) Alterations to prepulse inhibition magnitude and latency in adult rats following neonatal treatment with domoic acid and social isolation rearing. Behav Brain Res 298:310-317. CrossRef Medline

Miron O, Ari-Even Roth D, Gabis LV, Henkin Y, Shefer S, Dinstein I, Geva R (2016) Prolonged auditory brainstem responses in infants with autism. Autism Res 9:689-695. CrossRef Medline

Murphy E, Benítez-Burraco A (2016) Bridging the gap between genes and language deficits in schizophrenia: an oscillopathic approach. Front Hum Neurosci 10:422. CrossRef Medline

Murphy E, Benítez-Burraco A (2017) Language deficits in schizophrenia and autism as related oscillatory connectomopathies: an evolutionary account. Neurosci Biobehav Rev 83:742-764. CrossRef Medline

Newbury DF, Paracchini S, Scerri TS, Winchester L, Addis L, Richardson AJ, Walter J, Stein JF, Talcott JB, Monaco AP (2011) Investigation of dyslexia and SLI risk variants in reading- and language-impaired subjects. Behav Genet 41:90-104. CrossRef Medline

Nielsen DM, Derber WJ, McClellan DA, Crnic LS (2002) Alterations in the auditory startle response in Fmr1 targeted mutant mouse models of fragile X syndrome. Brain Res 927:8-17. CrossRef Medline

Peñagarikano O, Abrahams BS, Herman EI, Winden KD, Gdalyahu A, Dong H, Sonnenblick LI, Gruver R, Almajano J, Bragin A, Golshani P, Trachtenberg JT, Peles E, Geschwind DH (2011) Absence of CNTNAP2 leads to epilepsy, neuronal migration abnormalities, and core autismrelated deficits. Cell 147:235-246. CrossRef Medline

Perry W, Minassian A, Lopez B, Maron L, Lincoln A (2007) Sensorimotor gating deficits in adults with autism. Biol Psychiatry 61:482-486. CrossRef Medline

Pinnock F, Bosch D, Brown T, Simons N, Yeomans JR, DeOliveira C, Schmid $S$ (2015) Nicotine receptors mediating sensorimotor gating and its enhancement by systemic nicotine. Front Behav Neurosci 9:30. CrossRef Medline

Poliak S, Salomon D, Elhanany H, Sabanay H, Kiernan B, Pevny L, Stewart CL, Xu X, Chiu SY, Shrager P, Furley AJ, Peles E (2003) Juxtaparanodal clustering of shaker-like $\mathrm{K}+$ channels in myelinated axons depends on Caspr2 and TAG-1. J Cell Biol 162:1149-1160. CrossRef Medline

Poot M (2015) Connecting the CNTNAP2 networks with neurodevelopmental disorders. Mol Syndromol 6:7-22. CrossRef Medline

Poot M (2017) Intragenic CNTNAP2 deletions: a bridge too far? Mol Syndromol 8:118-130. CrossRef Medline

Popelar J, Grecova J, Rybalko N, Syka J (2008) Comparison of noiseinduced changes of auditory brainstem and middle latency response amplitudes in rats. Hear Res 245:82-91. CrossRef Medline

Robbins CA, Tempel BL (2012) Kv1.1 and Kv1.2: similar channels, different seizure models. Epilepsia 53:134-141. CrossRef Medline

Rodenas-Cuadrado P, Ho J, Vernes SC (2014) Shining a light on CNT- 
NAP2: complex functions to complex disorders. Eur J Hum Genet 22: 171-178. CrossRef Medline

Rodenas-Cuadrado P, Pietrafusa N, Francavilla T, La Neve A, Striano P, Vernes SC (2016) Characterisation of CASPR2 deficiency disorder - a syndrome involving autism, epilepsy and language impairment. BMC Med Genet 17:8. CrossRef Medline

Rosenhall U, Nordin V, Brantberg K, Gillberg C (2003) Autism and auditory brain stem responses. Ear Hear 24:206-214. CrossRef Medline

Roth DA, Muchnik C, Shabtai E, Hildesheimer M, Henkin Y (2012) Evidence for atypical auditory brainstem responses in young children with suspected autism spectrum disorders. Dev Med Child Neurol 54:23-29. CrossRef Medline

Rotschafer SE, Marshak S, Cramer KS (2015) Deletion of Fmr1 alters function and synaptic inputs in the auditory brainstem. PLoS One 10: e0117266. CrossRef Medline

Schormans AL, Scott KE, Vo AM, Tyker A, Typlt M, Stolzberg D, Allman BL (2016) Audiovisual temporal processing and synchrony perception in the rat. Front Behav Neurosci 10:246. CrossRef Medline

Sergeyenko Y, Lall K, Liberman MC, Kujawa SG (2013) Age-related cochlear synaptopathy: an early-onset contributor to auditory functional decline. J Neurosci 33:13686-13694. CrossRef Medline

Servadio M, Vanderschuren LJ, Trezza V (2015) Modeling autism-relevant behavioral phenotypes in rats and mice: Do "autistic" rodents exist? Behav Pharmacol 26:522-540. CrossRef Medline

Shi L, Chang Y, Li X, Aiken S, Liu L, Wang J (2016) Cochlear synaptopathy and noise-induced hidden hearing loss. Neural Plast 2016:6143164. CrossRef Medline

Simons-Weidenmaier NS, Weber M, Plappert CF, Pilz PK, Schmid S (2006) Synaptic depression and short-term habituation are located in the sensory part of the mammalian startle pathway. BMC Neurosci 7:38. CrossRef Medline

Sinclair D, Oranje B, Razak KA, Siegel SJ, Schmid S (2017) Sensory processing in autism spectrum disorders and fragile $\mathrm{X}$ syndrome: from the clinic to animal models. Neurosci Biobehav Rev 76:235-253. CrossRef Medline

Strauss KA, Puffenberger EG, Huentelman MJ, Gottlieb S, Dobrin SE, Parod JM, Stephan DA, Morton DH (2006) Recessive symptomatic focal epilepsy and mutant contactin-associated protein-like 2. N Engl J Med 354: 1370-1377. CrossRef Medline

Swerdlow NR, Caine SB, Braff DL, Geyer MA (1992) The neural substrates of sensorimotor gating of the startle reflex: a review of recent findings and their implications. J Psychopharmacol 6:176-190. CrossRef Medline

Takahashi H, Nakahachi T, Komatsu S, Ogino K, Iida Y, Kamio Y (2014) Hyperreactivity to weak acoustic stimuli and prolonged acoustic startle latency in children with autism spectrum disorders. Mol Autism 5:23. CrossRef Medline

Takahashi H, Komatsu S, Nakahachi T, Ogino K, Kamio Y (2016) Relationship of the acoustic startle response and its modulation to emotional and behavioral problems in typical development children and those with au- tism spectrum disorders. J Autism Dev Disord 46:534-543. CrossRef Medline

Tas A, Yagiz R, Tas M, Esme M, Uzun C, Karasalihoglu AR (2007) Evaluation of hearing in children with autism by using TEOAE and ABR. Autism 11:73-79. CrossRef Medline

Thomas AM, Schwartz MD, Saxe MD, Kilduff TS (2016) Cntnap2 knockout rats and mice exhibit epileptiform activity and abnormal sleep/wake physiology. Sleep 40. CrossRef Medline

Truong DT, Rendall AR, Castelluccio BC, Eigsti IM, Fitch RH (2015) Auditory processing and morphological anomalies in medial geniculate nucleus of Cntnap2 mutant mice. Behav Neurosci 129:731-743. CrossRef Medline

Typlt M, Mirkowski M, Azzopardi E, Ruettiger L, Ruth P, Schmid S (2013) Mice with deficient BK channel function show impaired prepulse inhibition and spatial learning, but normal working and spatial reference memory. PLoS One 8:e81270. CrossRef Medline

Valsamis B, Schmid S (2011) Habituation and prepulse inhibition of acoustic startle in rodents. J Vis Exp 55:e3446. CrossRef Medline

Vernes SC, Phil D, Newbury DF, Abrahams BS, Winchester L, Nicod J, Groszer M, Alarcón M, Oliver PL, Davies KE, Geschwind DH, Monaco AP, Fisher SE (2008) A functional genetic link between distinct developmental language disorders. N Engl J Med 359:2337-2345. CrossRef Medline

Weber M, Schnitzler HU, Schmid S (2002) Synaptic plasticity in the acoustic startle pathway: the neuronal basis for short-term habituation? Eur J Neurosci 16:1325-1332. CrossRef Medline

Whalley HC, O'Connell G, Sussmann JE, Peel A, Stanfield AC, HayiouThomas ME, Johnstone EC, Lawrie SM, McIntosh AM, Hall J (2011) Genetic variation in CNTNAP2 alters brain function during linguistic processing in healthy individuals. Am J Med Genet Part B Neuropsychiatr Genet 156:941-948. CrossRef Medline

Whitehouse AJ, Bishop DV, Ang QW, Pennell CE, Fisher SE (2011) CNTNAP2 variants affect early language development in the general population. Genes Brain Behav 10:451-456. CrossRef Medline

Wong V, Wong SN (1991) Brainstem auditory evoked potential study in children with autistic disorder. J Autism Dev Disord 21:329-340. CrossRef Medline

Yeomans JS, Lee J, Yeomans MH, Steidl S, Li L (2006) Midbrain pathways for prepulse inhibition and startle activation in rat. Neuroscience 142: 921-929. CrossRef Medline

Yu WM, Goodrich LV (2014) Morphological and physiological development of auditory synapses. Hear Res 311:3-16. CrossRef Medline

Yuhas J, Cordeiro L, Tassone F, Ballinger E, Schneider A, Long JM, Ornitz EM, Hessl D (2011) Brief report: sensorimotor gating in idiopathic autism and autism associated with fragile X syndrome. J Autism Dev Disord 41:248-253. CrossRef Medline

Zaman T, De Oliveira C, Smoka M, Narla C, Poulter MO, Schmid S (2017) BK channels mediate synaptic plasticity underlying habituation in rats. J Neurosci 37:4540-4551. CrossRef Medline 